\title{
ESTUDIO FLORÍSTICO DE LOS PIÑONARES DE PINUS PINCEANA GORDON
}

\author{
José Ángel Villarreal Quintanilla, Oscar Mares Arreola, \\ Eladio Cornejo Oviedo y Miguel A. Capó Arteaga \\ Universidad Autónoma Agraria Antonio Narro, \\ Departamento de Botánica y Departamento Forestal, \\ 25315 Buenavista Saltillo, Coahuila, México. \\ javqu05@yahoo.com.mx; mares.oscar@inifap.gob.mx
}

\section{RESUMEN}

Se presenta un estudio de la flora de 14 comunidades con Pinus pinceana Gordon. Esta especie forma pequeños bosques aislados a lo largo de la Sierra Madre Oriental, en el norte y centro de México. Se realizó un análisis de similitud florística entre las localidades estudiadas. Se reportan 446 especies, más 4 taxa infraespecíficas adicionales, distribuidas en 247 géneros y 78 familias. De acuerdo con su composición florística, las comunidades estudiadas se pueden separar en dos conjuntos: las más norteñas, localizadas en Coahuila, Zacatecas y San Luis Potosí, y las de la región sur en Querétaro e Hidalgo. Se concluye que existen dos grupos de piñonares de P. pinceana, con base en sus diferencias florísticas y de distribución.

Palabras clave: flora, México, Pinus pinceana, piñonares.

\begin{abstract}
A floristic study of 14 communities with Pinus pinceana Gordon was carried out. This species is distributed in small populations along the Sierra Madre Oriental in northern and central Mexico. A floristic similarity analysis between localities is included. A total of 446 species (plus 4 infaespecific taxa), 247 genera and 78 families were found. The communities can be separated by its flora into two groups: the northern one, located in Coahuila, Zacatecas and San Luis Potosí, and the southern one located in Querétaro and Hidalgo.
\end{abstract}


Key words: flora, Mexico, Pinus pinceana, pinion pine forests.

\section{INTRODUCCIÓN}

En México existen entre ocho y 15 especies de pinos piñoneros, las cuales están distribuidas en los estados del norte y centro del país. Estos pinos se encuentran desde Baja California, Baja California Sur, Sonora, Chihuahua, Coahuila, Nuevo León, Tamaulipas, Durango, Zacatecas, San Luis Potosí, hasta Aguascalientes, Guanajuato, Jalisco, Querétaro, Hidalgo, Tlaxcala, Puebla y Veracruz (Eguiluz, 1987; Farjon et al., 1997; Perry, 1991).

El grupo de pinos piñoneros está conformado por Pinus cembroides Zucc., P. culminicola Andresen et Beaman, P. maximartinezii Rzed., P. monophylla Torr. et Frém., P. nelsonii Shaw, P. pinceana Gordon, P. quadrifolia Parl. ex Sudw. y $P$. remota (Little) D. K. Bailey et Hawksw. (Farjon et al., 1997). Perry (1991), con un criterio más amplio, considera como parte de este conjunto también a las siguientes especies: P. catarinae Rob.-Pass., P. discolor D. K. Bailey et Hawksw., P. edulis Engelm., $P$. johannis Rob.-Pass., $P$. juarezensis Lanner y P. lagunae Passini.

Las comunidades de piñoneros, a pesar de su limitada capacidad productiva, aportan varios tipos de materiales y servicios ambientales que tienen impacto decisivo en la supervivencia de los poblados rurales. De ellas se obtienen semillas comestibles o piñones, leña, postes, madera para construcción de vivienda y muebles rústicos, árboles de navidad, resina, además de servir de abrigo a la fauna silvestre y en algunos casos como áreas de recreo. Las superficies de estas comunidades se han reducido notablemente en los últimos años y varias de ellas se encuentran amenazadas o en peligro de desaparecer debido a perturbaciones antropogénicas y naturales (Caballero y Ávila, 1989).

El pino piñonero liso, Pinus pinceana Gordon, es una conífera endémica de México. Su distribución comprende parte de los estados de Coahuila, Zacatecas, San Luis Potosí, Querétaro e Hidalgo. Está considerada como especie sujeta a protección especial en la Norma Oficial Mexicana NOM-059-ECOL-2001, por tener poblaciones muy restringidas y en pequeños rodales (Anónimo, 2001).

El interés por promover y llevar a cabo estudios florísticos se ha incrementado en los últimos años. Esto se debe, en gran medida, a la importancia que hoy en día tiene el conocimiento de la biodiversidad en el contexto de su conservación y aprovechamiento racional (Cabrera y Gómez, 2005; Villaseñor, 1991). Existen algunos antecedentes sobre estudios florísticos en comunidades de piñoneros, 
como los de Passini $(1982,1994)$, en especial en Pinus cembroides, P. johannis y $P$. discolor en el centro del país. Específicamente para $P$. pinceana, los trabajos encontrados en la literatura sólo cubren una parte de los piñonares de esta especie (Ávila, 1985; García, 2002; Hernández, 1985; López, 1996; Rebolledo, 1982; Romero et al., 1989).

Debido a que se desconocía la composición florística de los bosques de Pinus pinceana en toda su área de distribución, se realizó un inventario correspondiente en 14 de las comunidades naturales en que habita esta especie. Los objetivos son: 1) presentar un censo de referencia de las plantas vasculares que conforman la flora asociada a las poblaciones y 2) clasificar las comunidades estudiadas con base en la semejanza de su composición florística.

Área de estudio

Se recolectó en 14 sitios en que prospera Pinus pinceana (Cuadro 1), ubicados a lo largo de la Sierra Madre Oriental entre los 20 $37^{\prime} 53^{\prime \prime}$ a los $26^{\circ} 27^{\prime} 42^{\prime \prime} \mathrm{N}$ y los 98 58'31" a los 101041'16" W (Fig. 1). Su localización corresponde a las provincias fisiográficas de los Pliegues Saltillo-Parras (El Recreo), Sierras Transversales (El Cinco, Palmas Altas, Santa Elena, Cañón de las Bocas, Lomas del Orégano, San José de Carbonerillas), Sierras y Llanuras Coahuilenses (Las Norias), Sierras y Llanuras Occidentales (Matehualilla y La Trinidad), Sierras y Llanuras del norte de Guanajuato (Maguey Verde y El Tepozán) y Karst Huasteco (El Arenalito y San Cristóbal) (Cervantes et al., 1990). La población de Las Norias en Cuatro Ciénegas Coah., es la más septentrional y la de San Cristóbal en Cardonal Hgo., la más meridional de la distribución conocida para esta especie.

Las altitudes se ubican entre los 1750 y los $2500 \mathrm{~m}$ (Cuadro 1), las pendientes varían entre 12 y 66 por ciento. En general prevalece la exposición norte, a excepción de Palmas Altas, Lomas del Orégano y Matehualilla, en donde se registra la dirigida hacia el sur. El material geológico es de origen sedimentario y la unidad litológica dominante es la caliza, asociada frecuentemente con lutitas y conglomerados. Los suelos predominantes son litosoles, con textura media, asociados con castañozems, fluvisoles, regosoles y rendzinas (Anónimo, 1983).

El clima del área de distribución es seco (BS de la clasificación de Koppen), en algunos lugares templado ( $\mathrm{C}$, de acuerdo con la misma categorización), con lluvias en verano, extremoso, con una precipitación media anual que va desde los $350 \mathrm{~mm}$ hasta los $650 \mathrm{~mm}$ y una temperatura media anual de 14 a $18^{\circ} \mathrm{C}$ (García, 1987). 


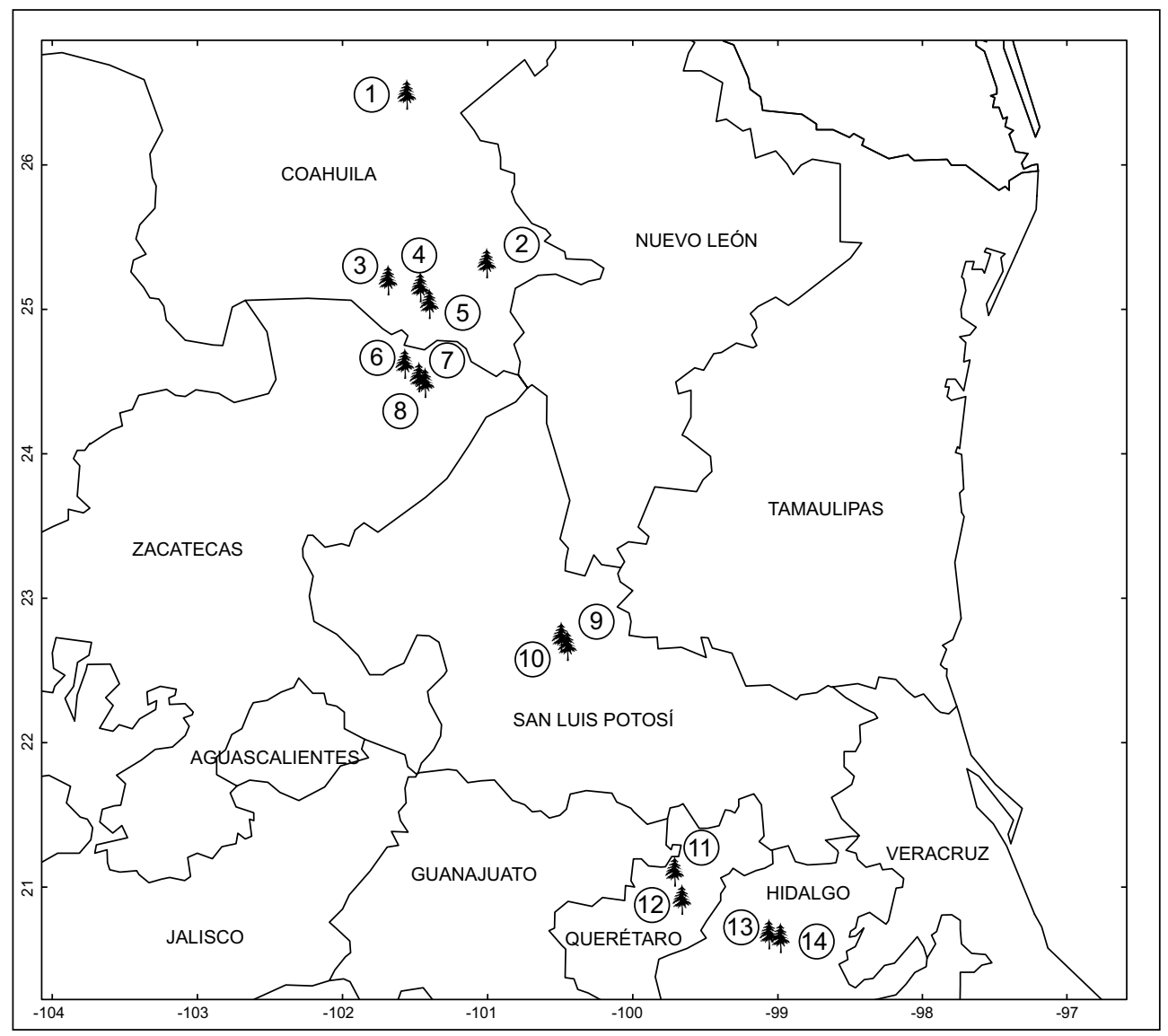

1. Las Norias

2. El Recreo

3. El Cinco

4. Palmas Altas

5. Santa Elena

6. Cañón de las Bocas

7. Lomas del Orégano
Poblaciones:

8. San José de Carbonerillas

9. Matehualilla

10. La Trinidad

11. Maguey Verde

12. El Tepozán

13. El Arenalito

14. San Cristóbal

Fig. 1. Ubicación de las 14 poblaciones naturales muestreadas de Pinus pinceana Gordon para el presente estudio. 
Cuadro 1. Ubicación geográfica y altitud de las localidades muestreadas de Pinus pinceana Gordon en los estados de Coahuila, Zacatecas, San Luis Potosí, Querétaro e Hidalgo. Fuente: CETENAL. Cartas F14 A65, 72; F14 C33, 41, 42, 47, 58, 62, 65, 72 .

\begin{tabular}{|c|c|c|}
\hline Nombre de la localidad & Ubicación geográfica & Altitud (m s.n.m.) \\
\hline Las Norias, Cuatrociénegas, Coah. & $26^{\circ} 27^{\prime} 42.2^{\prime \prime}$ у $101^{\circ} 34^{\prime} 24.5^{\prime \prime}$ & 1800 \\
\hline El Recreo, Saltillo, Coah. & $25^{\circ} 17^{\prime} 40.5^{\prime \prime}$ y $101^{\circ} 00^{\prime} 02.4^{\prime \prime}$ & 2280 \\
\hline El Cinco, Parras, Coah. & $25^{\circ} 10^{\prime} 41.3^{\prime \prime}$ у $101^{\circ} 41^{\prime} 16.8^{\prime \prime}$ & 2200 \\
\hline Palmas Altas, Saltillo, Coah. & $25^{\circ} 07^{\prime} 57.7^{\prime \prime}$ y $101^{\circ} 27^{\prime} 04.6^{\prime \prime}$ & 2300 \\
\hline Santa Elena, Saltillo, Coah. & $25^{\circ} 01^{\prime} 38.1^{\prime \prime}$ у $101^{\circ} 24^{\prime} 29.6^{\prime \prime}$ & 2200 \\
\hline Cañón de las Bocas, Mazapil, Zac. & $24^{\circ} 36^{\prime} 37.3^{\prime \prime}$ y $101^{\circ} 34^{\prime} 31.7^{\prime \prime}$ & 2500 \\
\hline Lomas del Orégano, Mazapil, Zac. & $24^{\circ} 30^{\prime} 19.1^{\prime \prime}$ y $101^{\circ} 27^{\prime} 48.2^{\prime \prime}$ & 2300 \\
\hline San José Carbonerillas, Mazapil, Zac. & $24^{\circ} 28^{\prime} 19.1^{\prime \prime}$ y $101^{\circ} 26^{\prime} 53.4^{\prime \prime}$ & 2250 \\
\hline $\begin{array}{l}\text { Matehualilla, Ejido Núñez, } \\
\text { Guadalcázar, S.L.P. }\end{array}$ & $22^{\circ} 42^{\prime} 32.6^{\prime \prime}$ y $100^{\circ} 28^{\prime} 05.7^{\prime \prime}$ & 2000 \\
\hline $\begin{array}{l}\text { La Trinidad, Ejido Núñez, } \\
\text { Guadalcázar, S.L.P. }\end{array}$ & $22^{\circ} 40^{\prime} 06.2^{\prime \prime}$ y $100^{\circ} 28^{\prime} 24.2^{\prime \prime}$ & 1950 \\
\hline Maguey Verde, Peñamiller, Qro. & $21^{\circ} 05^{\prime} 25.8^{\prime \prime}$ y $99^{\circ} 41^{\prime} 58.4^{\prime \prime}$ & 2200 \\
\hline El Tepozán, Cadereyta, Qro. & $20^{\circ} 54^{\prime} 23.5^{\prime \prime}$ у 99³9' $21.0^{\prime \prime}$ & 2200 \\
\hline El Arenalito, Cardonal, Hgo. & $20^{\circ} 39^{\prime} 27.7^{\prime \prime}$ y $99^{\circ} 02^{\prime} 58.9^{\prime \prime}$ & 1900 \\
\hline San Cristóbal, Cardonal, Hgo. & $20^{\circ} 37^{\prime} 53.2^{\prime \prime}$ y $98^{\circ} 58^{\prime} 31.5^{\prime \prime}$ & 1750 \\
\hline
\end{tabular}

\section{MÉTODOS}

El material botánico se recolectó en el periodo del 29 de marzo del 2004 al 18 de diciembre del 2005. Su juego más importante se depositó en el herbario ANSM (herbario de la Universidad Autónoma Agraria Antonio Narro). Para la identificación de los ejemplares se usaron principalmente las floras regionales de Henrickson y Johnston (1997) y Rzedowski et al. (2001), y se les cotejó con los de la colección del herbario ANSM. En la elaboración del listado florístico se siguió la nomenclatura de la Flora de Coahuila (Villarreal, 2001) con algunas actualizaciones y para la escritura de los autores a Villaseñor (2001).

La clasificación numérica o multivariable de las 14 comunidades, de acuerdo con su similitud florística, se obtuvo a partir de una matriz de presencia o ausencia, conformada por 450 hileras (total de especies más taxa infaespecíficos adicionales registrados) y 14 columnas, correspondientes a los sitios estudiados. El coeficiente 
de similitud empleado fue el de Jaccard (Sneath y Sokal, 1973), y se utilizó la estrategia aglomerativa de la media aritmética sin ponderación (UPGMA, siglas en inglés de Unweighted Pair-Group Method using Arithmetic averages). El análisis de los datos se realizó con el programa computacional NTSYS, versión 2.02, desarrollado por Rohlf (2000).

\section{RESULTADOS Y DISCUSIÓN}

Se encontró que la flora vascular asociada a las poblaciones de Pinus pincea$n a$ Gordon está representada por un total de 446 especies más 4 taxa infraespecificas adicionales, comprendidas en 247 géneros y 78 familias de plantas vasculares (Cuadro 2). La lista completa correspondiente se presenta en el Anexo.

Las familias mejor representadas son: Asteraceae con 46 géneros y 89 especies (46/89), que constituyen $20 \%$ del total de las últimas, Fabaceae con 18/40 (9\%), Cactaceae con 15/37 (8.3\%), Poaceae con 20/40 (9\%), Scrophulariaceae con 7/16 (3.5\%), Euphorbiaceae con 6/13 (2.9\%), Rosaceae con 6/10 (2.2\%), Pteridaceae con 5/9 (2\%), Agavaceae con 4/14 (3.1\%) y Lamiaceae con 4/13 (2.9\%). A estas 10 familias pertenecen 131 géneros y 281 especies registradas, las cuales constituyen el 63.1 por ciento de la flora registrada.

Los géneros con mayor diversidad son: Salvia con 10 especies, Opuntia (sensu lato), Quercus y Muhlenbergia con ocho cada uno, Agave con siete, Acacia con seis y Rhus, Senna y Viguiera con cinco cada uno.

Cuadro 2. Grupos principales componentes de la flora vascular de las comunidades de Pinus pinceana Gordon.

\begin{tabular}{lcccc}
\hline Grupo taxonómico & Familias & Géneros & Especies & Especies (\%) \\
\hline Pteridophyta & 2 & 6 & 12 & 2.7 \\
Pinophyta & 3 & 3 & 8 & 1.8 \\
Magnoliophyta & & & & \\
Liliopsida & 7 & 35 & $71(+1$ var. $)$ & 16.0 \\
Magnoliopsida & 66 & 203 & $355(+1$ var.+2 ssp.) & 79.5 \\
Total & 78 & 247 & $446(+4$ taxa infra- & 100 \\
& & & específicos $)$ & \\
\hline
\end{tabular}


La composición florística de las comunidades donde crece $P$. pinceana muestra una combinación de especies propias de bosque de encinos con elementos de matorral, presentándose como una forma de transición entre comunidades de vegetación xerófila y mesófila.

Las localidades de Maguey Verde, Matehualilla, El Arenalito y Las Norias registraron el mayor número de especies. Su ubicación es aleatoria, sin tener un patrón espacial regular de asociación a lo largo del área de distribución. A su vez las de Palmas Altas, San José de Carbonerillas y El Cinco, ubicadas en el sur de Coahuila y norte de Zacatecas resultaron ser las más pobres desde el punto de vista de su flora (Cuadro 3).

Cuadro 3. Número de especies por localidad muestreada de Pinus pinceana Gordon.

\begin{tabular}{lclc}
\hline \multicolumn{1}{c}{ Localidad (nombre) } & Núm. especies & \multicolumn{1}{c}{ Localidad (nombre) } & Núm. especies \\
\hline Las Norias & 98 & San José de Carbonerillas & 51 \\
El Recreo & 86 & Matehualilla & 98 \\
El Cinco & 54 & La Trinidad & 80 \\
Palmas Altas & 44 & Maguey Verde & 103 \\
Santa Elena & 63 & El Tepozán & 83 \\
Cañón de las Bocas & 73 & El Arenalito & 98 \\
Lomas del Orégano & 61 & San Cristóbal & 76 \\
\hline
\end{tabular}

El dendrograma de la fig. 2 muestra la existencia de tres grupos o conjuntos de comunidades, de acuerdo con su composición florística y el valor del coeficiente de similitud (Cuadro 4). Uno de estos conjuntos ocupa la parte superior del árbol, con los inventarios de Coahuila y Zacatecas, donde separa la localidad de Las Norias, la más septentrional y con mayor grado de diferenciación dentro del grupo. El segundo conjunto se ubica en la porción media del dendrograma, muestra relación con el primero y lo forman dos comunidades (La Trinidad y Matehualilla) del estado de San Luis Potosí, y ocupa una posición intermedia en el gradiente latitudinal de los sitios estudiados (Fig. 1). El tercer grupo se encuentra en la parte inferior de la figura y está formado por las cuatro comunidades correspondientes a las localidades de Hidalgo (San Cristóbal, El Arenalito) y Querétaro (Maguey Verde, Tepozán). 


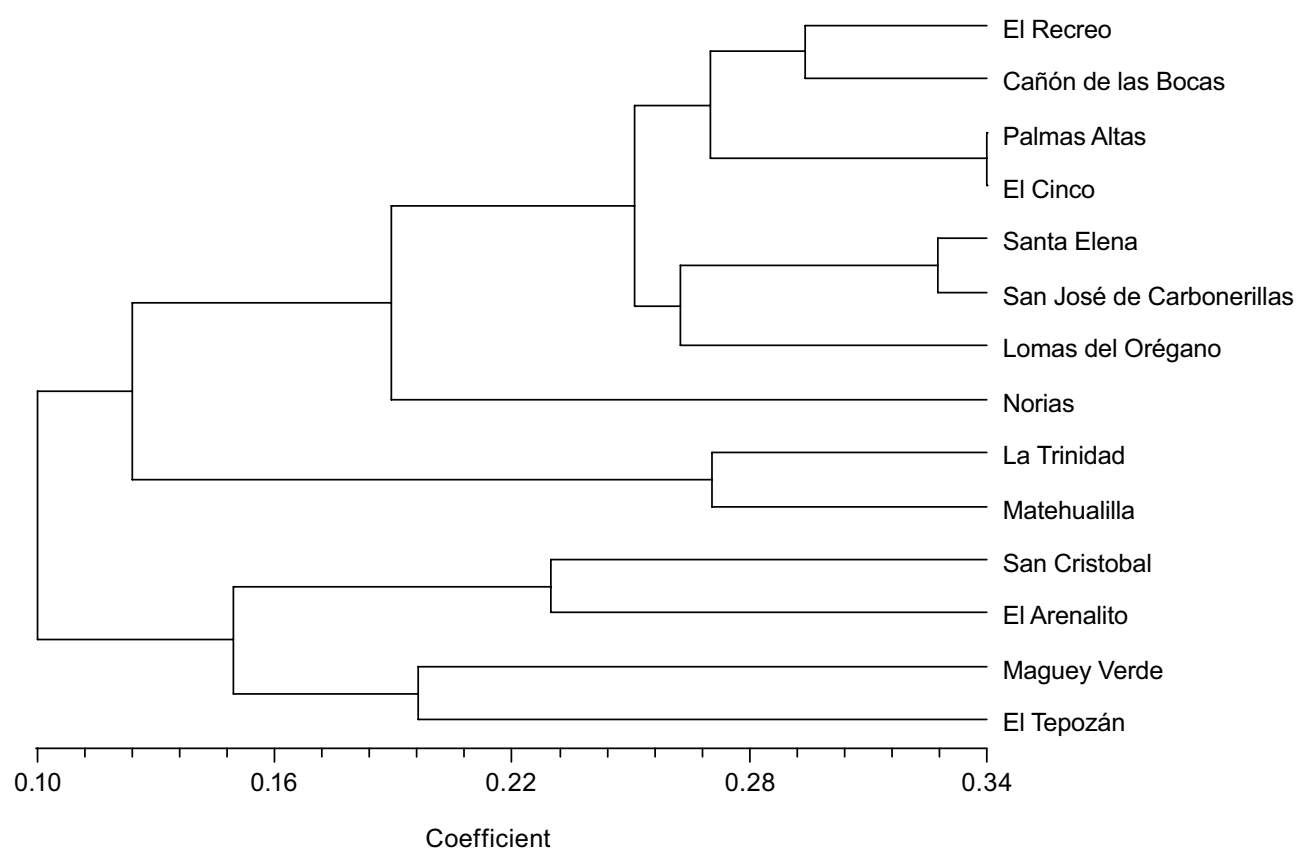

Fig. 2. Dendrograma que muestra la clasificación de las comunidades de Pinus pinceana Gordon, con base en la similitud de su composición florística.

Cada uno de estos tres grupos de comunidades con $P$. pinceana, presenta también diferentes condiciones ecológicas. Las localidades del tercero son las más meridionales, con mayor precipitación media anual (400 a $600 \mathrm{~mm}$ ) y mejor representación de elementos florísticos neotropicales. El primero, corresponde a los rodales más septentrionales (Las Norias a Santa Elena), caracterizados por menor cantidad de lluvia (350 a $400 \mathrm{~mm}$ ). El segundo es intermedio en la precipitación recibida (400 a $500 \mathrm{~mm}$ ), y al igual que el primero presenta mayor influencia holártica. Los inventarios de San Luis Potosí, aunque podrían considerarse como intermedios entre los otros dos grupos, son florísticamente más semejantes a los del primero, sin menoscabo de una alta incidencia de endemismos.

Con base en estos resultados, en las comunidades con $P$. pinceana pueden distinguirse dos conjuntos florísticamente diferentes: los de la región norte (Coahuila, Zacatecas y San Luis Potosí) y los de la región sur (Querétaro e Hidalgo). 
Villarreal Quintanilla et al.: Estudio florístico de los piñonares de Pinus pinceana

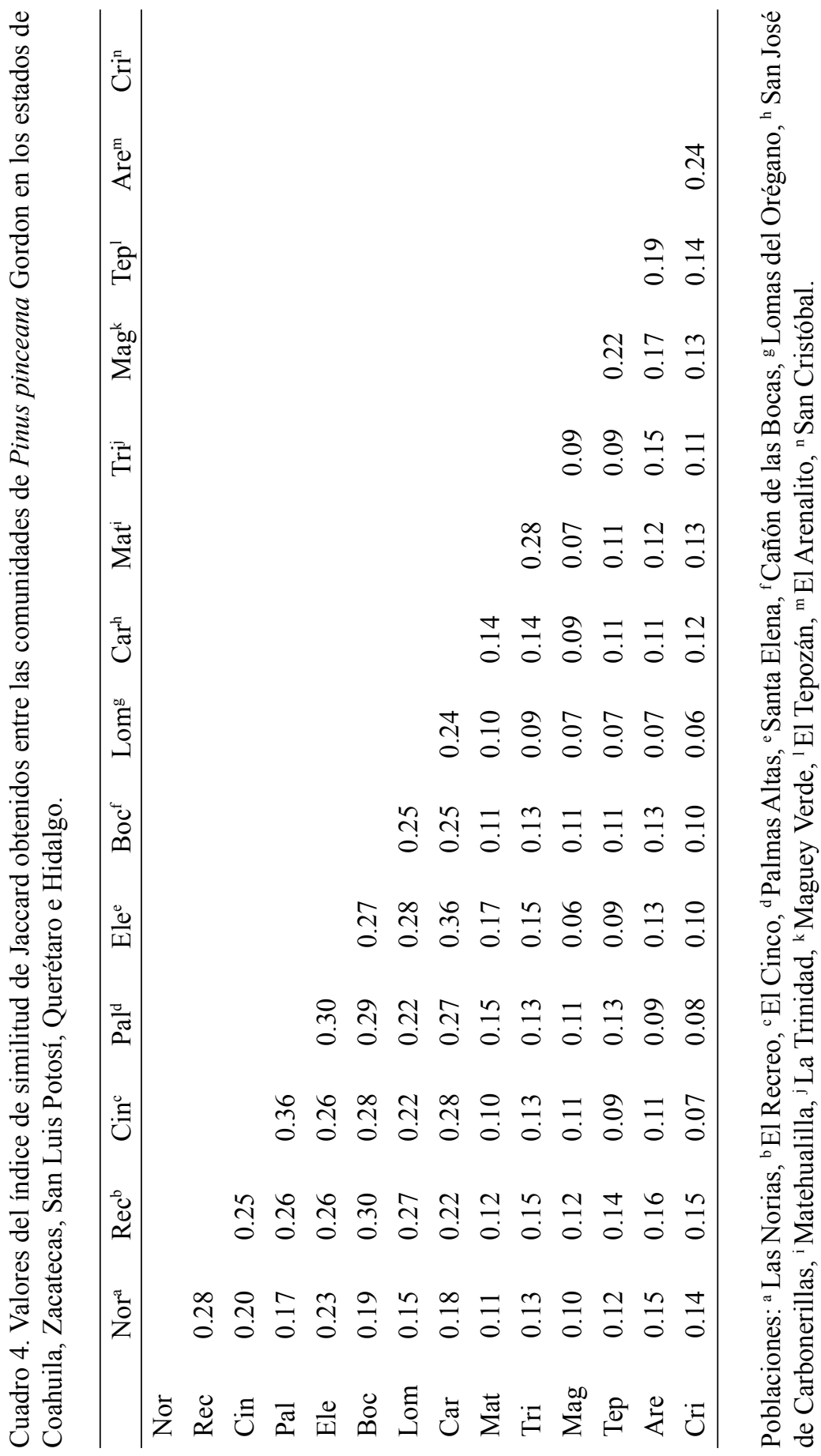




\section{AGRADECIMIENTOS}

Este trabajo es parte del proyecto Ecología, Genética de Poblaciones y Estrategias de conservación de poblaciones naturales de Pinus pinceana, financiado por el fondo sectorial SEMARNAT-CONACYT con clave CO1-1429. Recibió apoyo de la Universidad Autónoma Agraria Antonio Narro, a través de los proyectos 0205 2503 y 02032633 . Forma parte de la tesis de maestría del segundo autor. Se agradece a Miguel Sosa Morales y a Julián Charles Álvarez por su apoyo en las colectas y trabajo de campo, y a los revisores anónimos del escrito.

\section{LITERATURA CITADA}

Anónimo. 1983. Síntesis geográfica de Coahuila, México. Secretaría de Programación y Presupuesto. Instituto Nacional de Estadística, Geografía e Informática. México, D.F. 163 pp.

Anónimo. 2001. Norma Oficial Mexicana. NOM-059-ECOL-2001. Protección ambientalEspecies nativas de México de flora y fauna silvestres - Categorías de riesgo y especificaciones para su inclusión, exclusión o cambio - Lista de especies en riesgo. Secretaria del Medio Ambiente y Recursos Naturales. Diario Oficial de la Federación. México, D.F. 40 pp.

Ávila, A. 1985. Caracterización de los piñoneros Pinus cembroides Zucc. y P. discolor Bailey \& Hawks., de las serranías meridionales del estado de San Luis Potosí, México. Tesis de licenciatura. Facultad de Biología, Universidad Michoacana de San Nicolás de Hidalgo. Morelia, Mich. $101 \mathrm{pp}$.

Caballero, M. y R. Ávila. 1989. Importancia actual y potencial de los piñoneros en México. In: Flores, J. D., L. J. Flores, M. E. García y R. H. Lira (comp.). Memorias del III Simposio Nacional Sobre Pinos Piñoneros. Universidad Autónoma Agraria Antonio Narro - Instituto Nacional de Investigaciones Forestales, Agrícolas y Pecuarias. Saltillo, Coah. pp 18-22.

Cabrera, J. A. y M. Gómez. 2005. Análisis florístico de La Cañada, municipio El Marqués, Querétaro. Biologia Scripta 2(2): 49-62.

Cervantes, Y., S. L. Cornejo, R. Lucero, J. M. Espinoza, E. Miranda y A. Pineda. 1990. Clasificación de regiones naturales de México II. IV. 10.2. Atlas Nacional de México. Vol. II. Escala 1: 4,000,000. Instituto de Geografía, Universidad Nacional Autónoma de México. México, D.F.

Eguiluz, T. 1987. Evolución de los pinos piñoneros mexicanos. In: Passini, M. F., D. Cibrián y T. Eguiluz (comp.). II Simposio Nacional Sobre Pinos Piñoneros. Centre d'Études Mexicaines et Centraméricaines - Centro de Genética Forestal A.C. - Universidad Autónoma de Chapingo. México, D.F. pp. 83-89. 
Farjon, A., J. A. Pérez de la Rosa y B. Styles. 1997. A field guide to the pines of Mexico and Central America. The Royal Botanical Garden, Kew and the University of Oxford. Oxford, UK. 146 pp.

García, E. 1987. Modificaciones al sistema de clasificación climática de Köppen (adaptado a las condiciones de la República Mexicana). 4a. ed. Instituto de Geografía, Universidad Nacional Autónoma de México. México, D.F. 217 pp.

García, H. 2002. Caracterización de hábitats de coníferas que ameritan protección en el estado de Hidalgo. Tesis de licenciatura. División de Ciencias Forestales, Universidad Autónoma de Chapingo. Chapingo, Edo. de México. 256 pp.

Henrickson, J. and M. C. Johnston. 1997. A flora of the Chihuahuan Desert Region. (Draft version). Published by J. Henrickson. Los Ángeles, California. 1687 pp.

Hernández, A. 1985. Análisis estructural de los piñonares del Altiplano Potosino - Zacatecano. Tesis de maestría en ciencias. Colegio de Postgraduados. Chapingo, Edo. de México. 153 pp.

López, V. H. 1996. Estudio sinecológico de los bosques piñoneros del Valle del Mezquital, Hidalgo. Tesis de licenciatura. Escuela Nacional de Estudios Profesionales Iztacala, Universidad Nacional Autónoma de México. Los Reyes Iztacala, Tlanepantla, Edo. de México. 75 pp.

Passini, M. F. 1982. Les forêts de Pinus cembroides au Mexique. Mission Archaeologique et Ethnologique Française au Mexique, Études Mésoaméricaines II-5. Paris: Editions Recherche sur les Civilsations - Cahier No 9. Paris. 373 pp.

Passini, M. F. 1994. Relevés floristiques des forêts de pins pignons au Mexique (florística de los piñoneros en México). Université Pierre et Marie Curie. Paris 6. 124 pp.

Perry, J. 1991. The pines of Mexico and Central America. Timber Press. Portland, Oregon. $231 \mathrm{pp}$.

Rebolledo, A. 1982. Estudio preliminar sobre la ecología de los piñonares en el Altiplano Potosino - Zacatecano. Tesis de maestría en ciencias. Colegio de Postgraduados. Chapingo, Edo. de México. 112 pp.

Rohlf, F. J. 2000. NTSYS-pc numerical taxonomy and multivariate analysis system. Version 2.02. State University of New York. Nueva York. 178 pp.

Romero, A., M. Luna y E. García. 1989. Organización de la vegetación asociada a los piñonares de las sierras meridionales de San Luis Potosí. In: Flores, J. D., L. J. Flores, M. E. García y R. H. Lira (comp.). Memorias del III Simposio Nacional Sobre Pinos Piñoneros. Universidad Autónoma Agraria Antonio Narro - Instituto Nacional de Investigaciones Forestales, Agrícolas y Pecuarias. Saltillo, Coah. pp. 66-71

Rzedowski, G. C. de, J. Rzedowski y colaboradores. 2001. Flora fanerogámica del Valle de México. 2a. ed. Instituto de Ecología, A.C. y Comisión Nacional para el Conocimiento y Uso de la Biodiversidad. Pátzcuaro, Mich. 1406 pp.

Sneath, P. H. A. y R. R. Sokal. 1973. Numerical taxonomy. W. H. Freeman. San Francisco, California. 573 pp. 
Villarreal, J. A. 2001. Flora de Coahuila. Listados florísticos de México. Instituto de Biología, Universidad Nacional Autónoma de México. México, D.F. 136 pp.

Villaseñor, J. L. 1991. Las Heliantheae endémicas de México: una guía hacia la conservación. Acta Bot. Mex. 15: 29-46.

Villaseñor, J. L. 2001. Catálogo de autores de plantas vasculares de México. Instituto de Biología, Universidad Nacional Autónoma de México - Comisión Nacional para el Conocimiento y Uso de la Biodiversidad. México, D.F. 40 pp. 
Villarreal Quintanilla et al.: Estudio florístico de los piñonares de Pinus pinceana

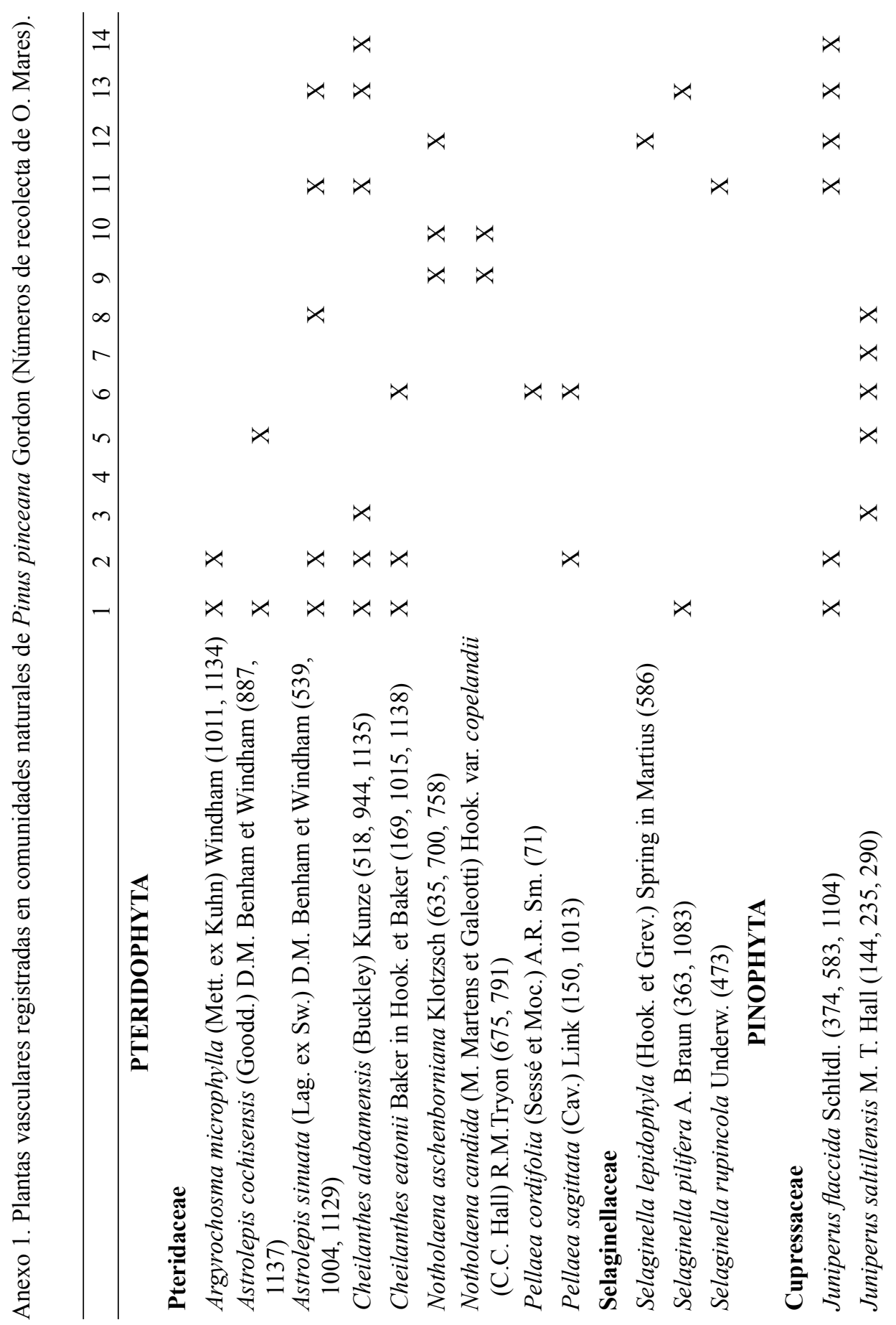


Acta Botanica Mexicana 89: 87-124 (2009)

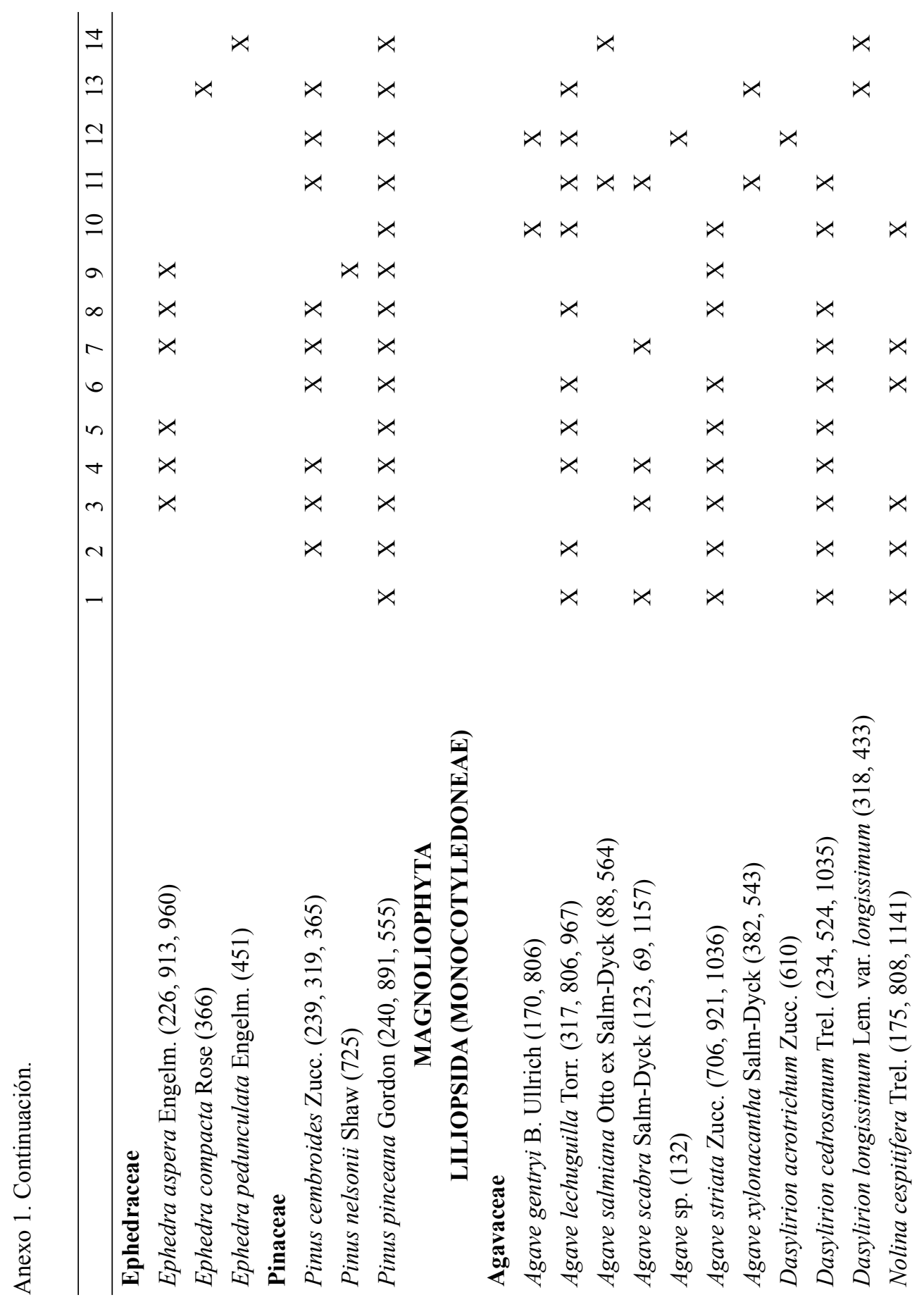


Villarreal Quintanilla et al.: Estudio florístico de los piñonares de Pinus pinceana

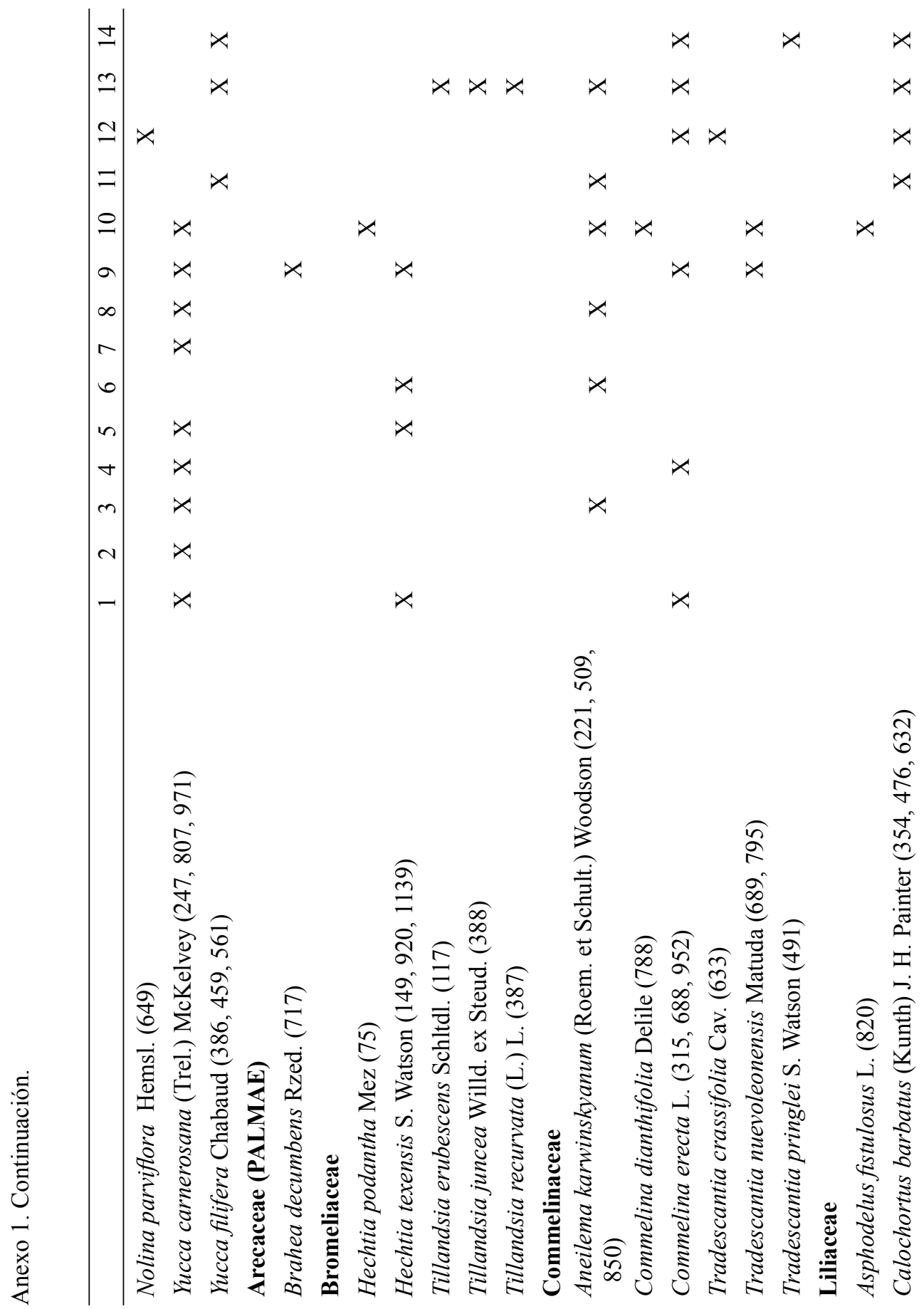


Acta Botanica Mexicana 89: 87-124 (2009)

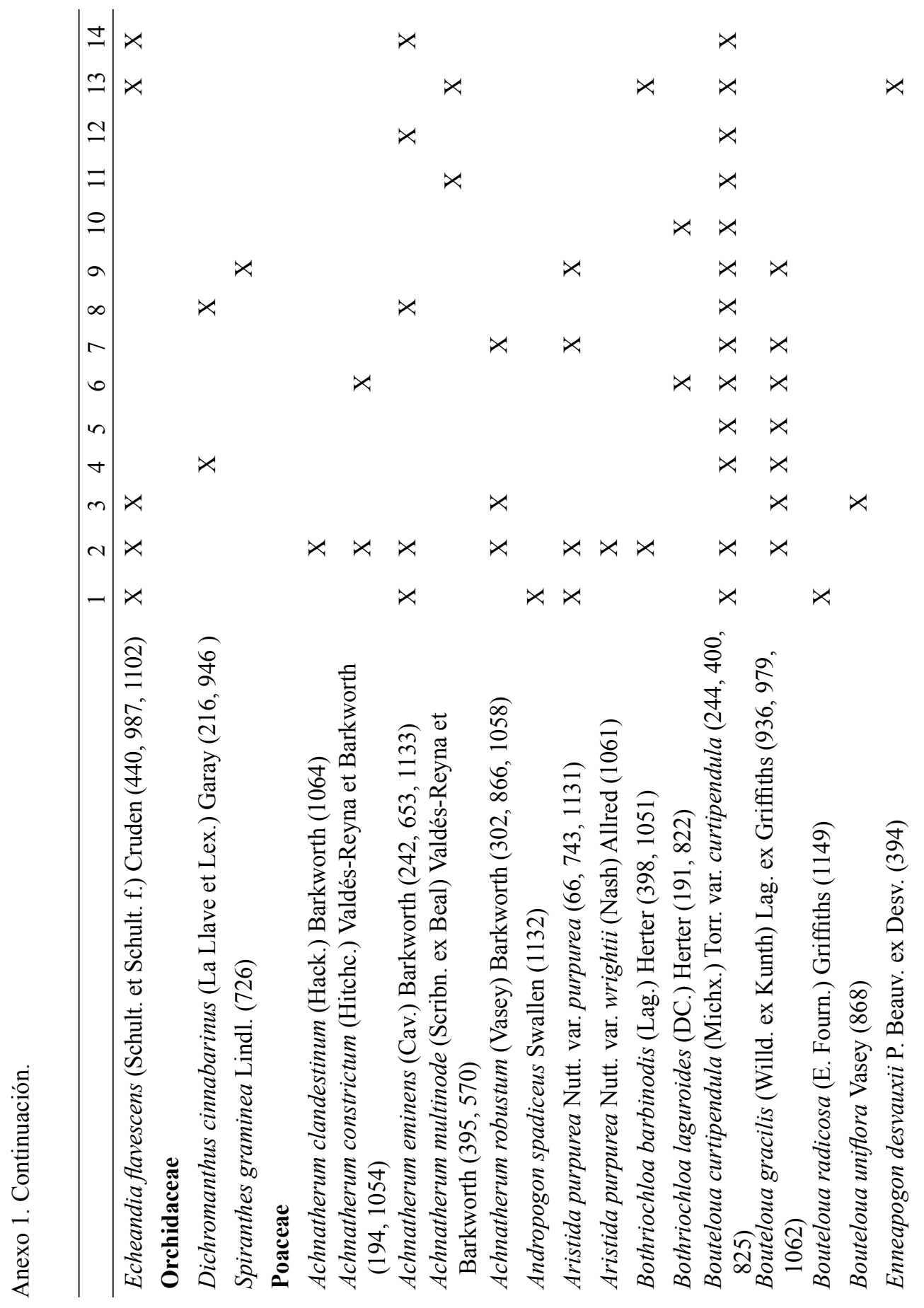


Villarreal Quintanilla et al.: Estudio florístico de los piñonares de Pinus pinceana

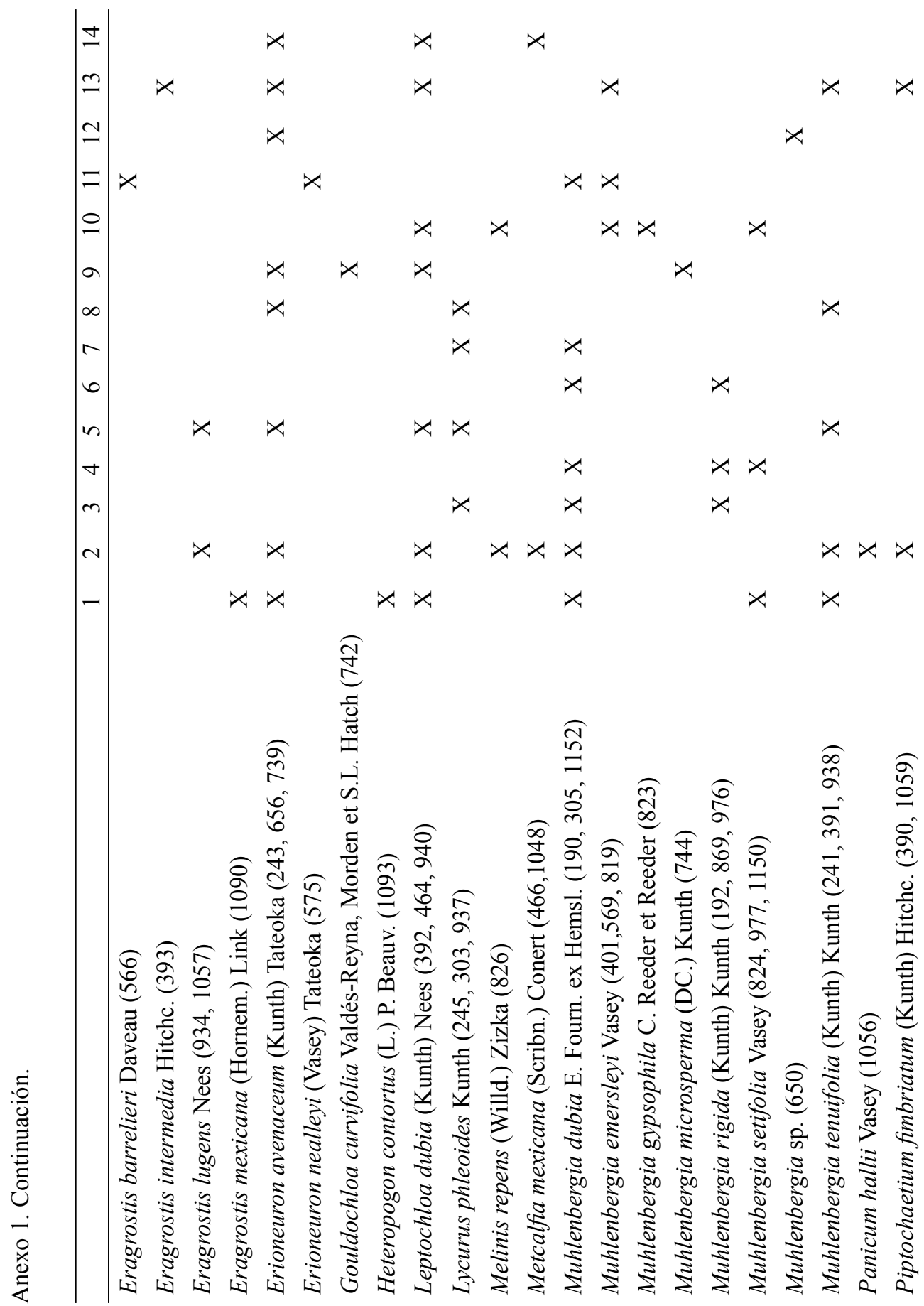


Acta Botanica Mexicana 89: 87-124 (2009)

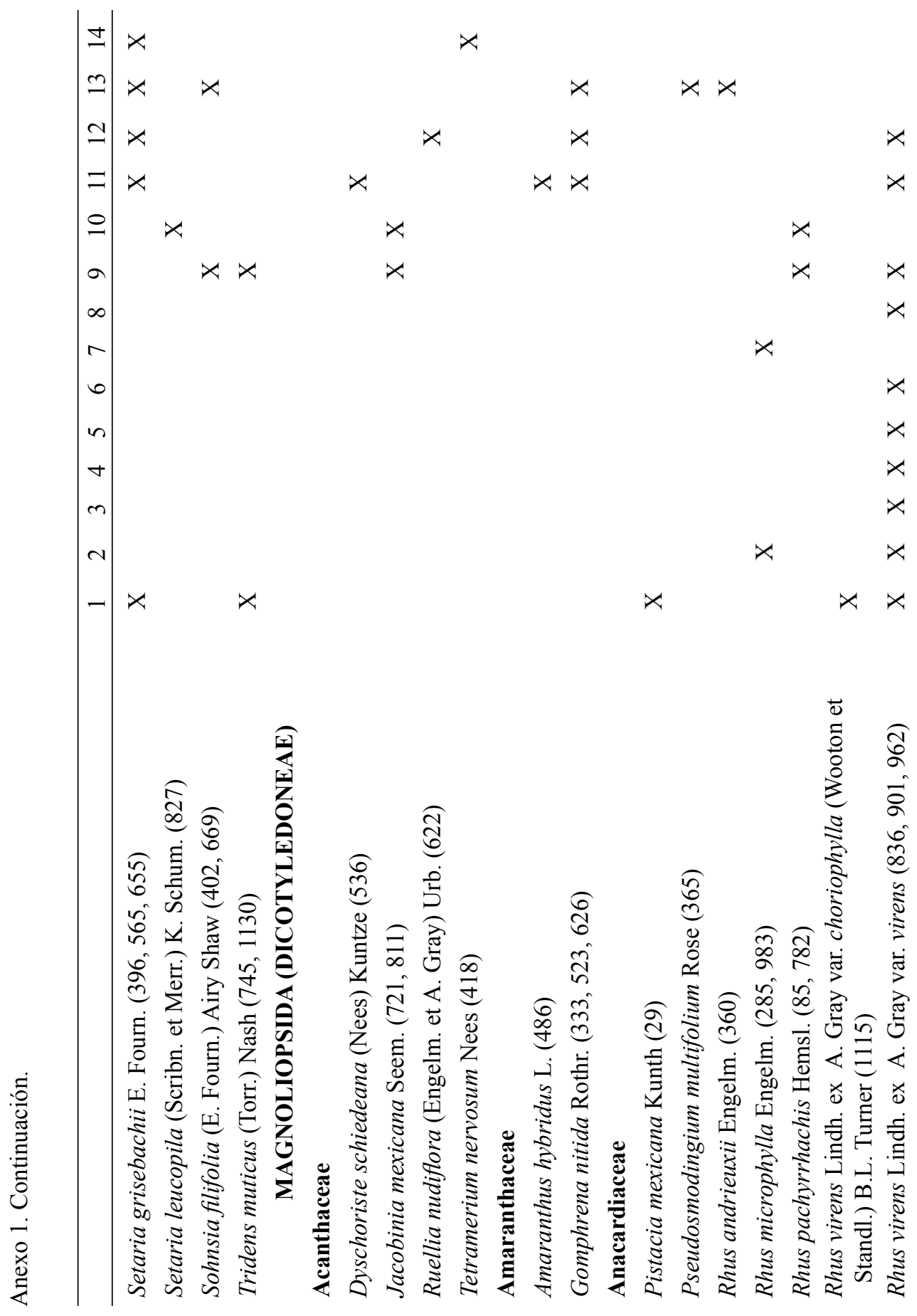


Villarreal Quintanilla et al.: Estudio florístico de los piñonares de Pinus pinceana

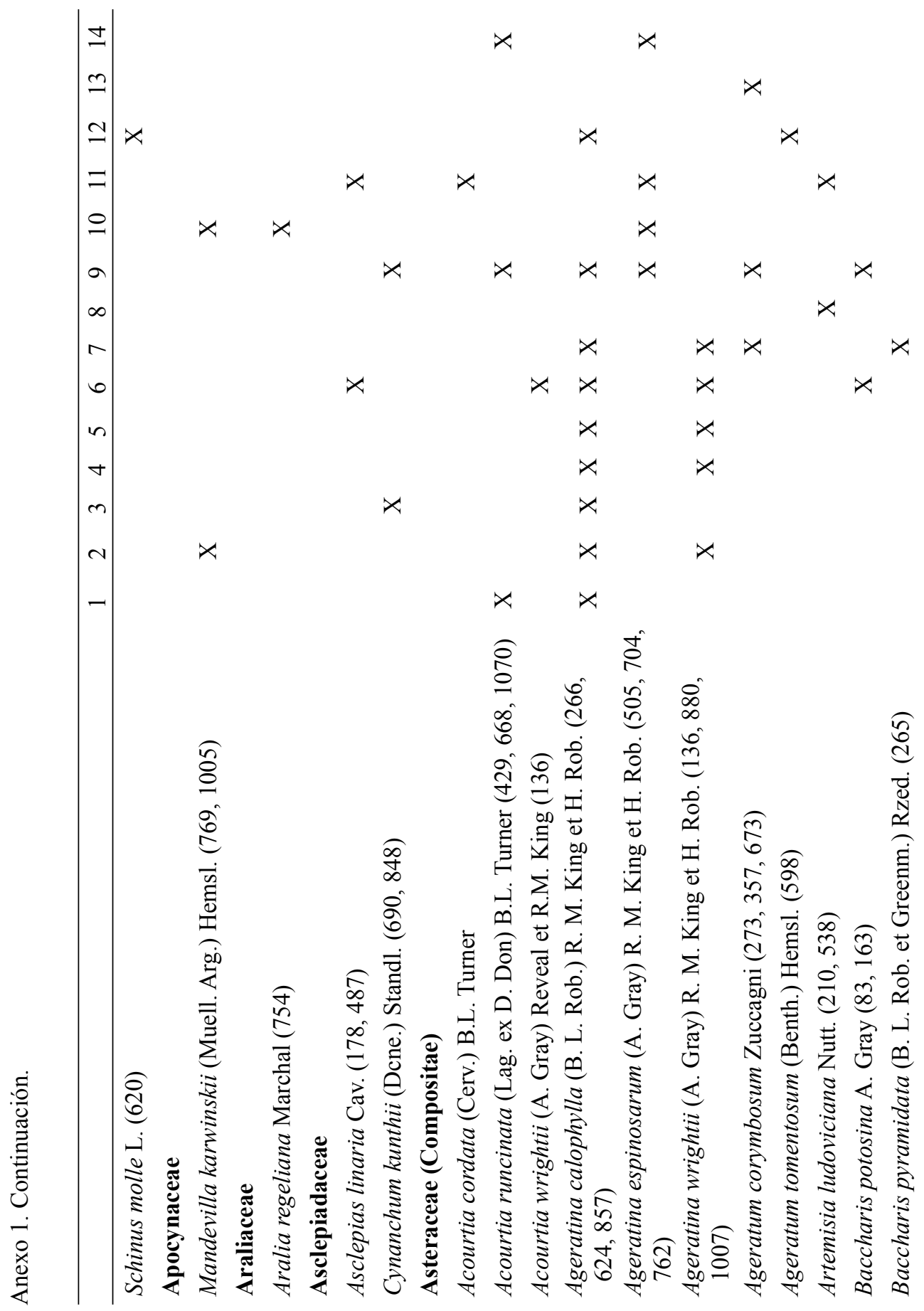


Acta Botanica Mexicana 89: 87-124 (2009)

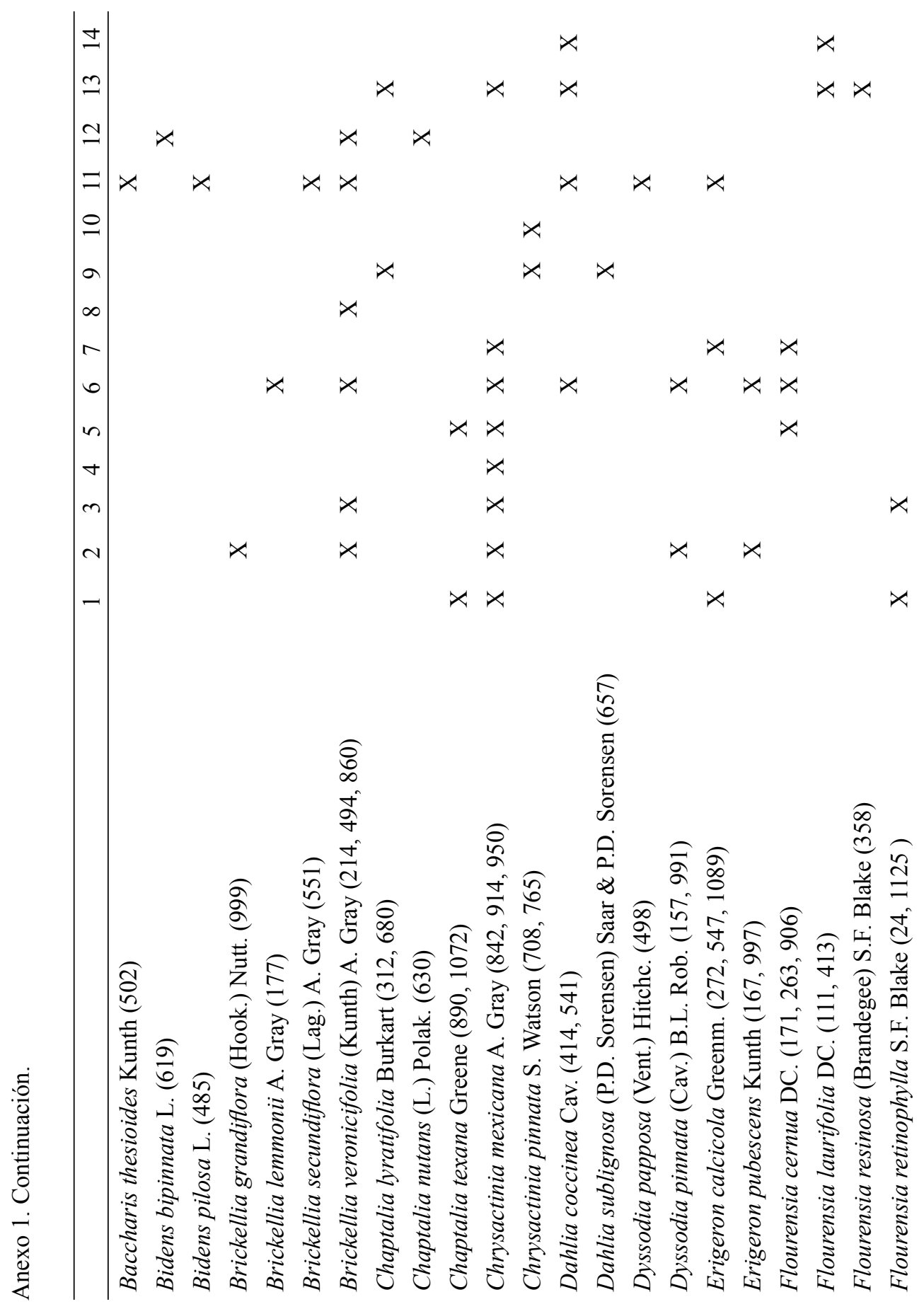


Villarreal Quintanilla et al.: Estudio florístico de los piñonares de Pinus pinceana

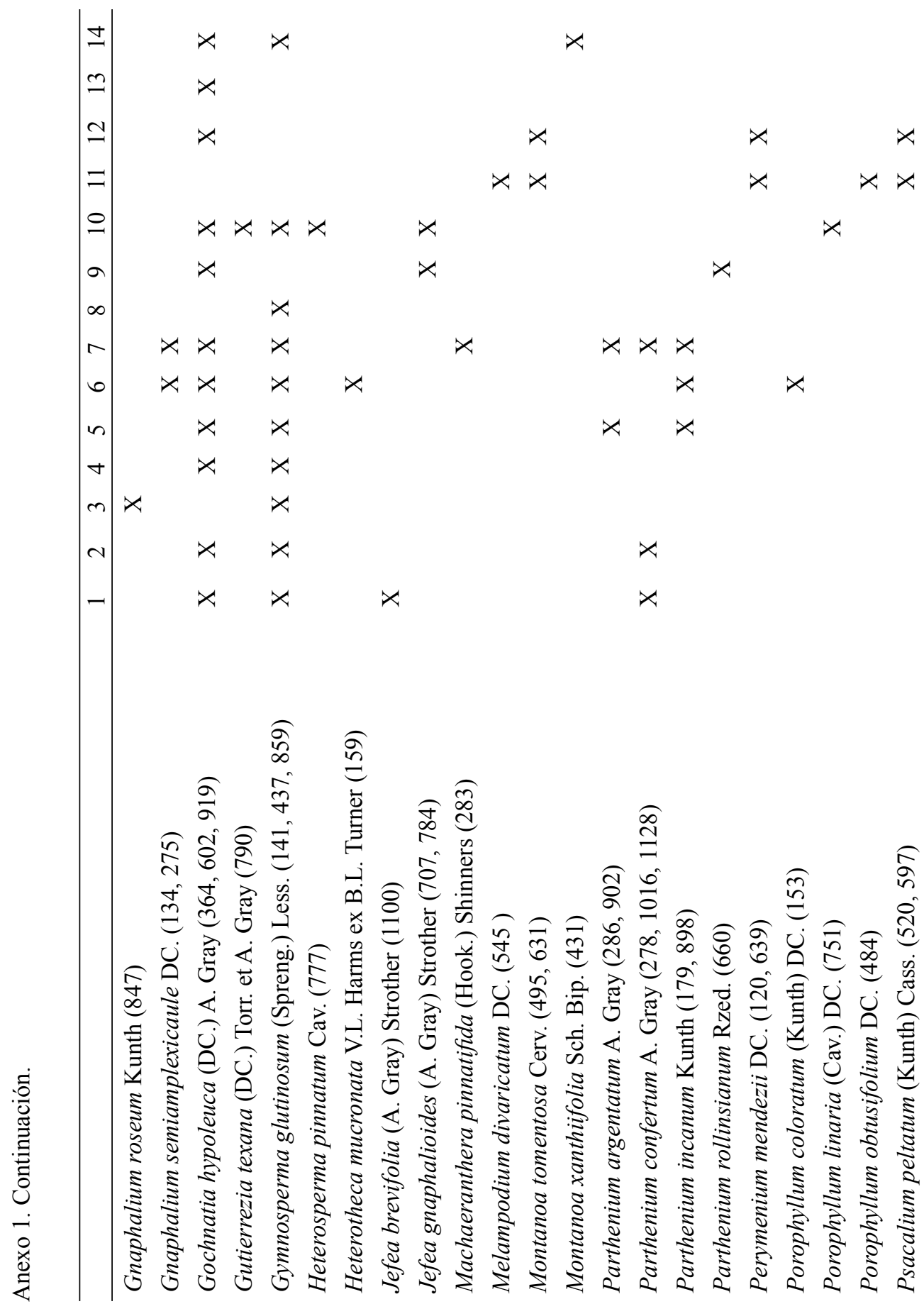


Acta Botanica Mexicana 89: 87-124 (2009)

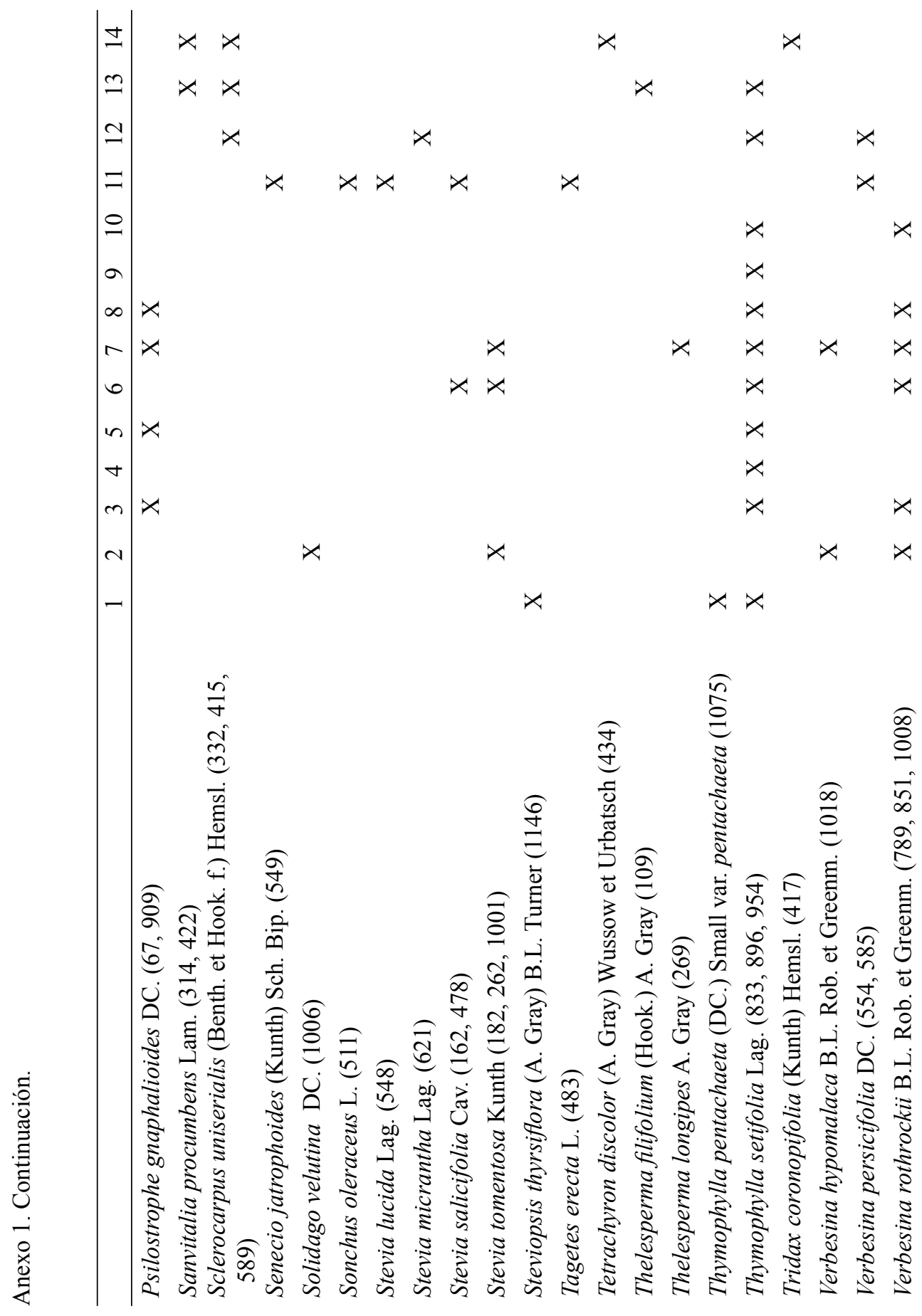


Villarreal Quintanilla et al.: Estudio florístico de los piñonares de Pinus pinceana

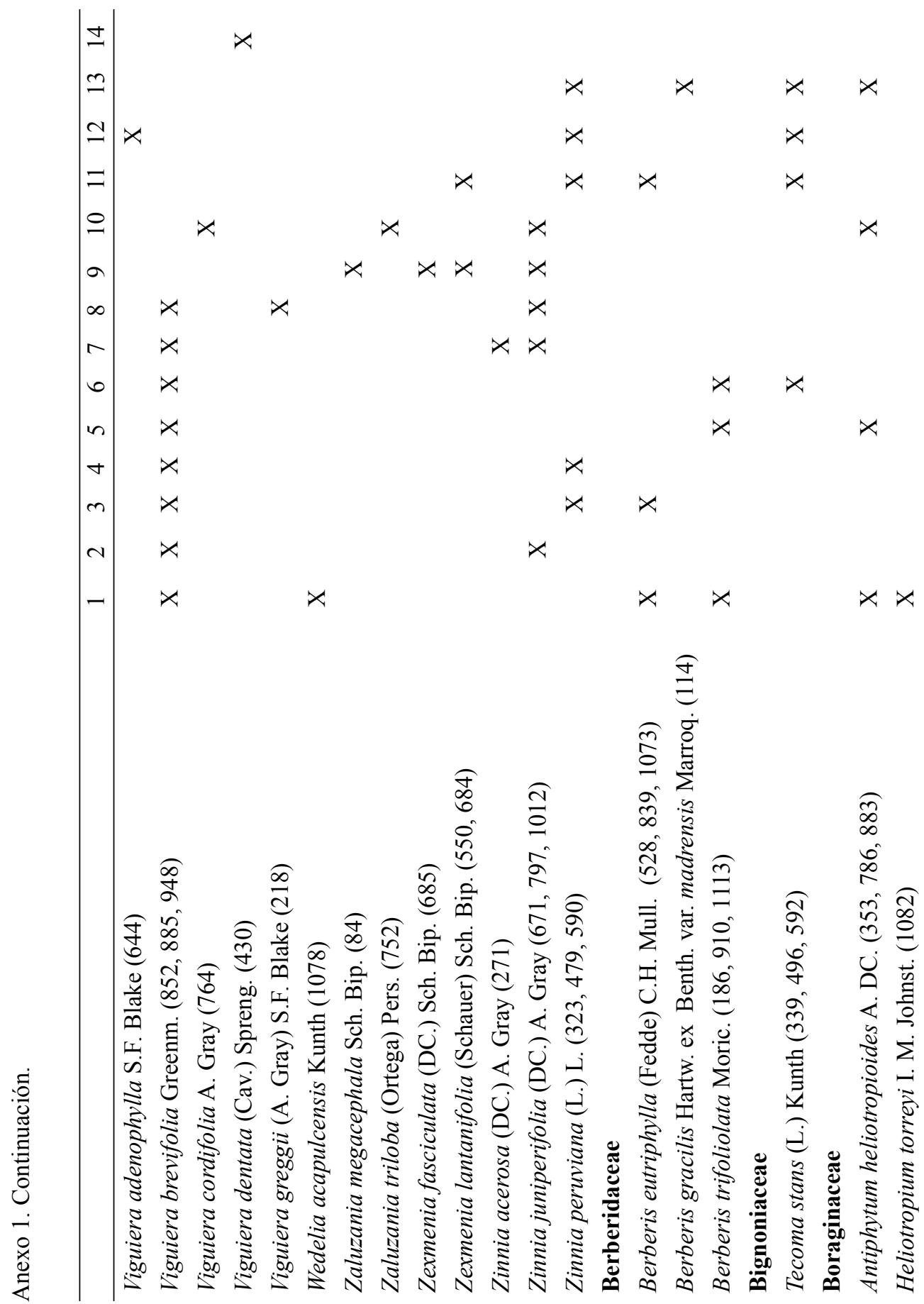


Acta Botanica Mexicana 89: 87-124 (2009)

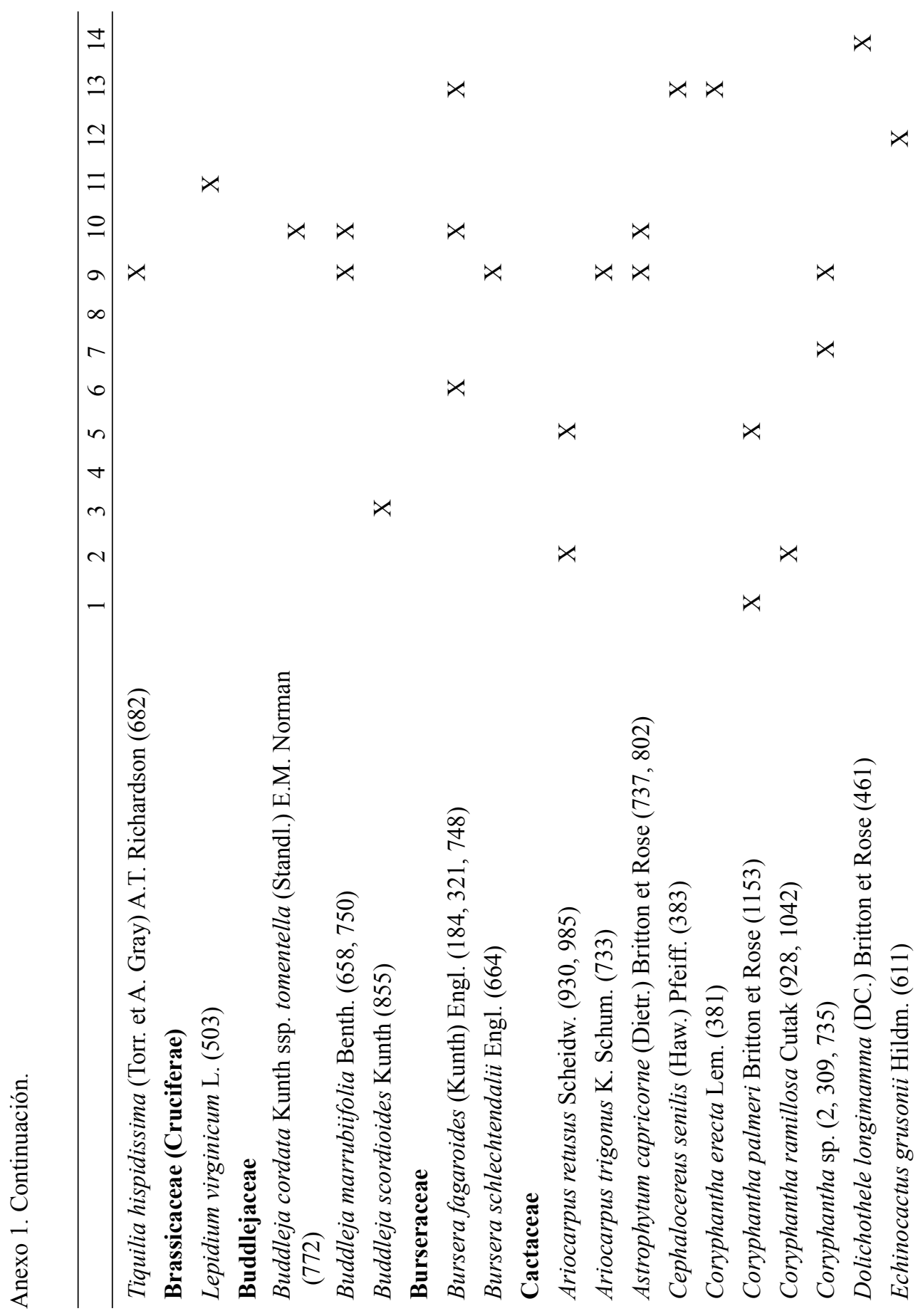


Villarreal Quintanilla et al.: Estudio florístico de los piñonares de Pinus pinceana

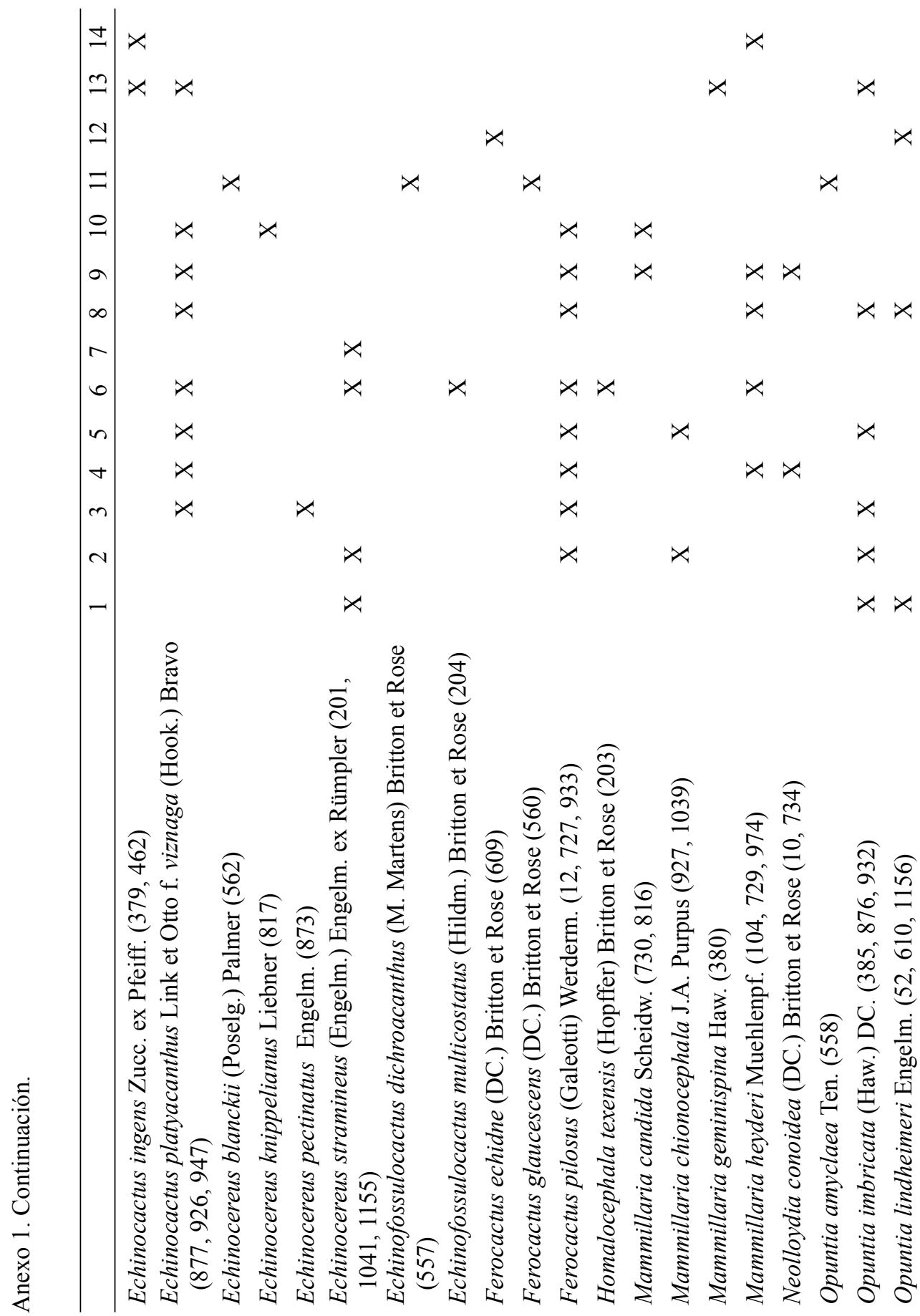


Acta Botanica Mexicana 89: 87-124 (2009)

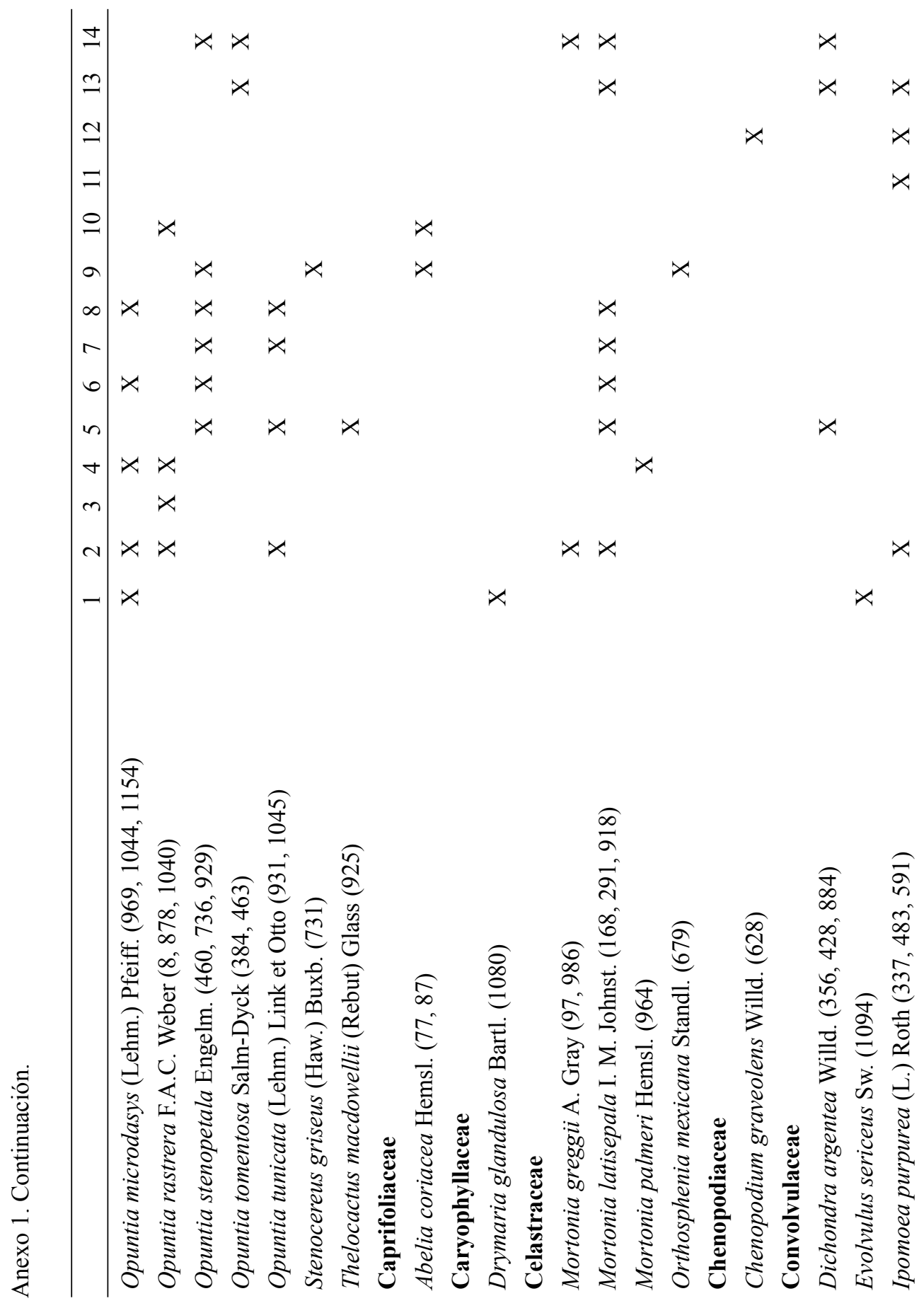


Villarreal Quintanilla et al.: Estudio florístico de los piñonares de Pinus pinceana

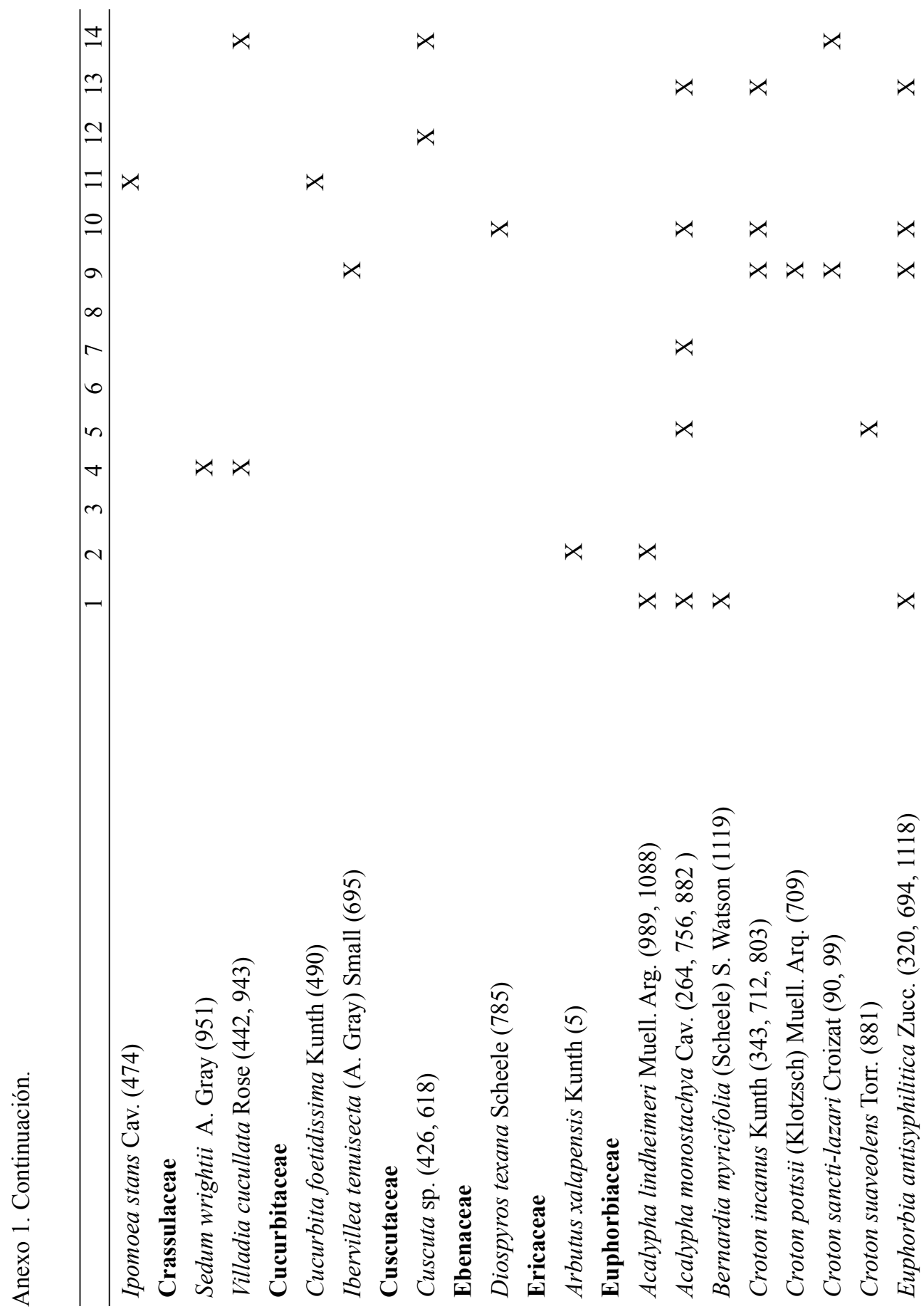


Acta Botanica Mexicana 89: 87-124 (2009)

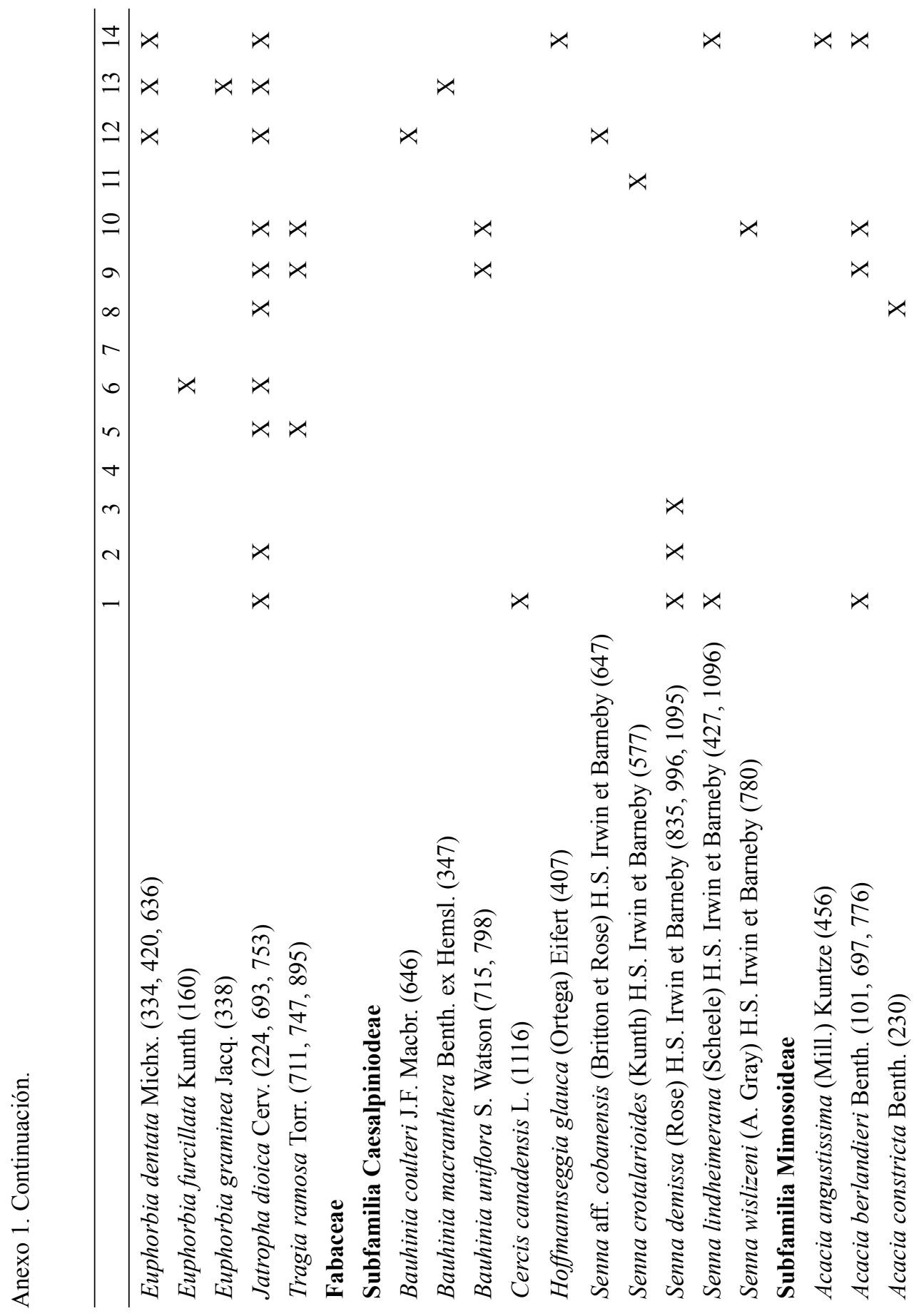


Villarreal Quintanilla et al.: Estudio florístico de los piñonares de Pinus pinceana

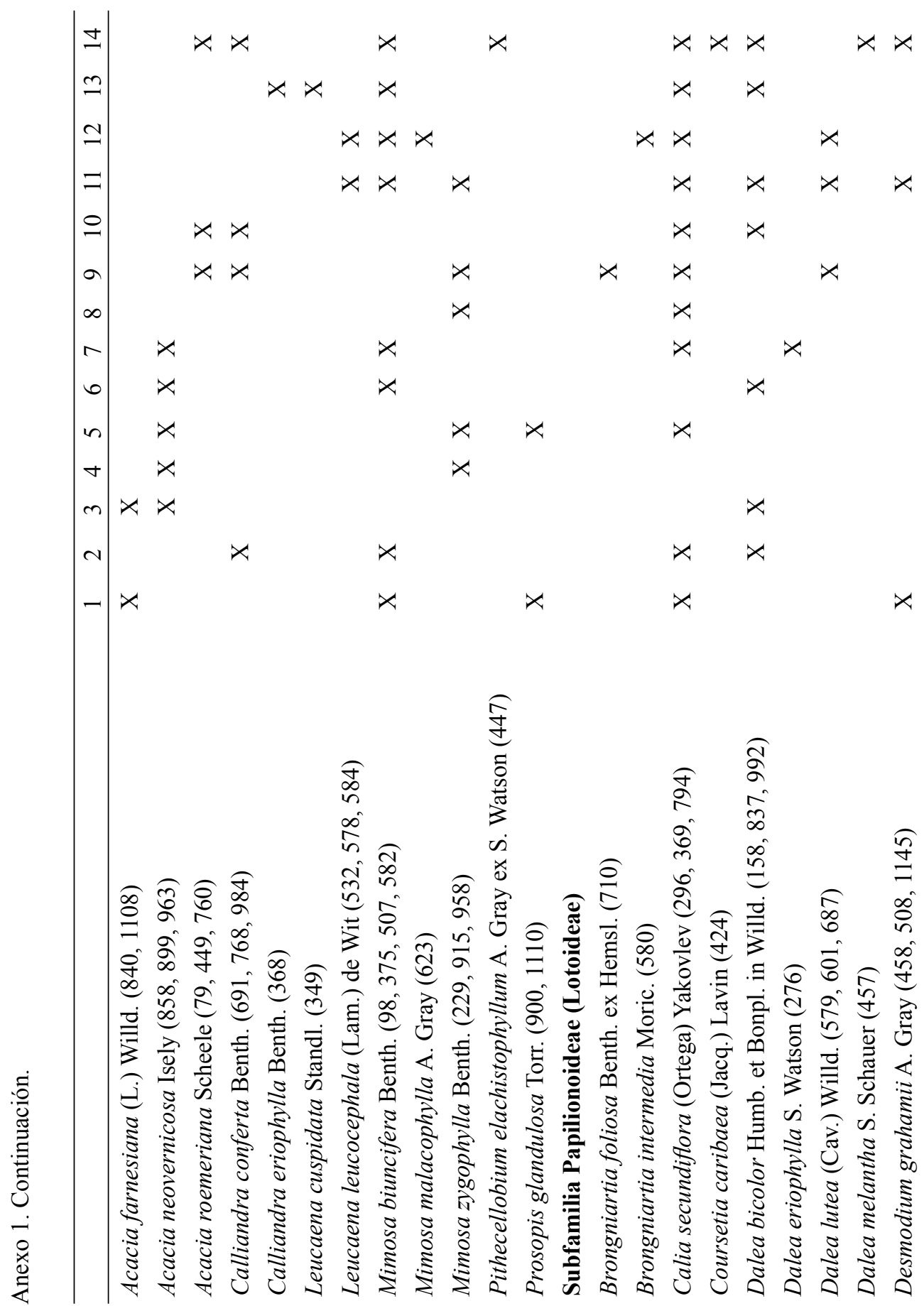


Acta Botanica Mexicana 89: 87-124 (2009)

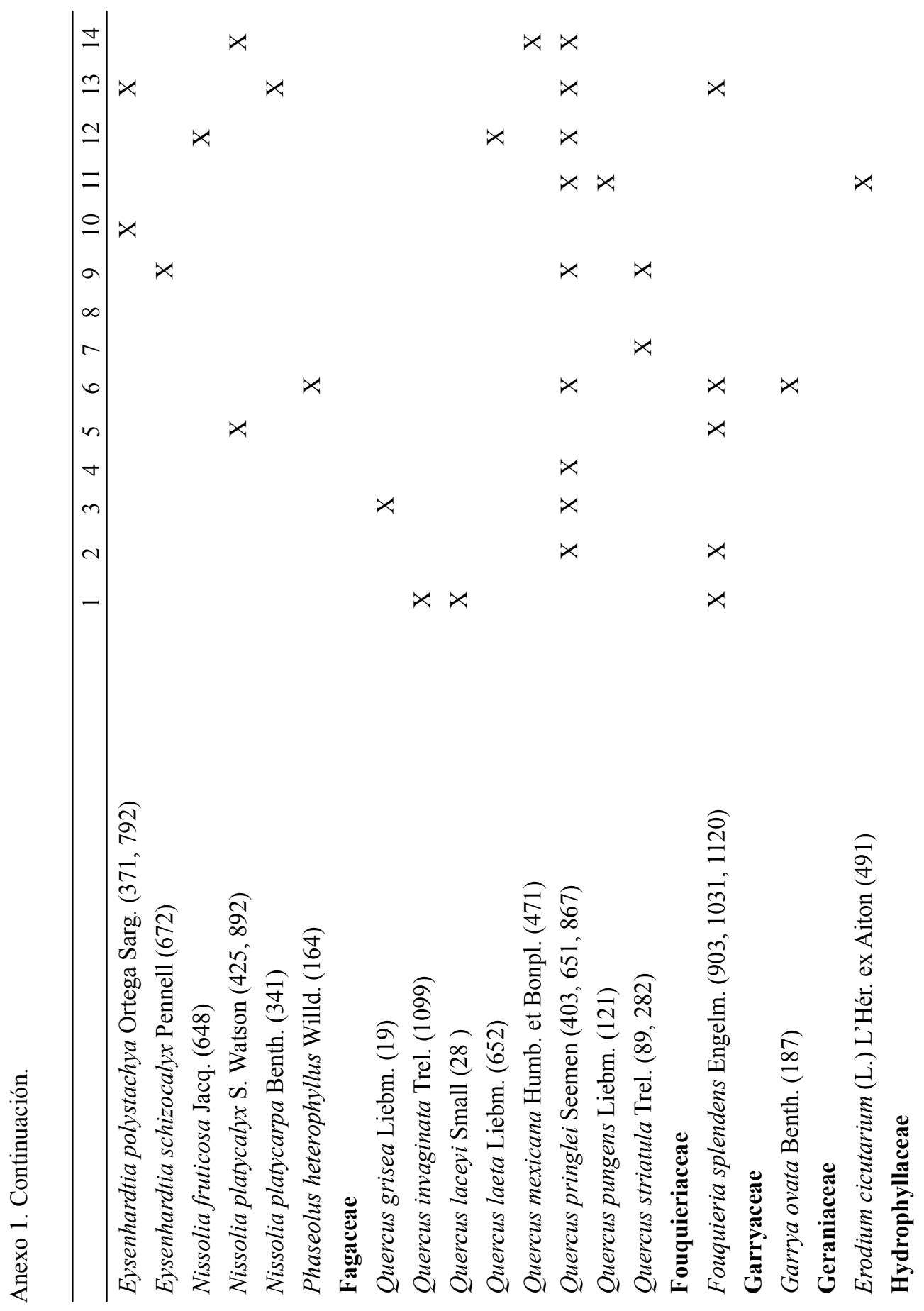


Villarreal Quintanilla et al.: Estudio florístico de los piñonares de Pinus pinceana

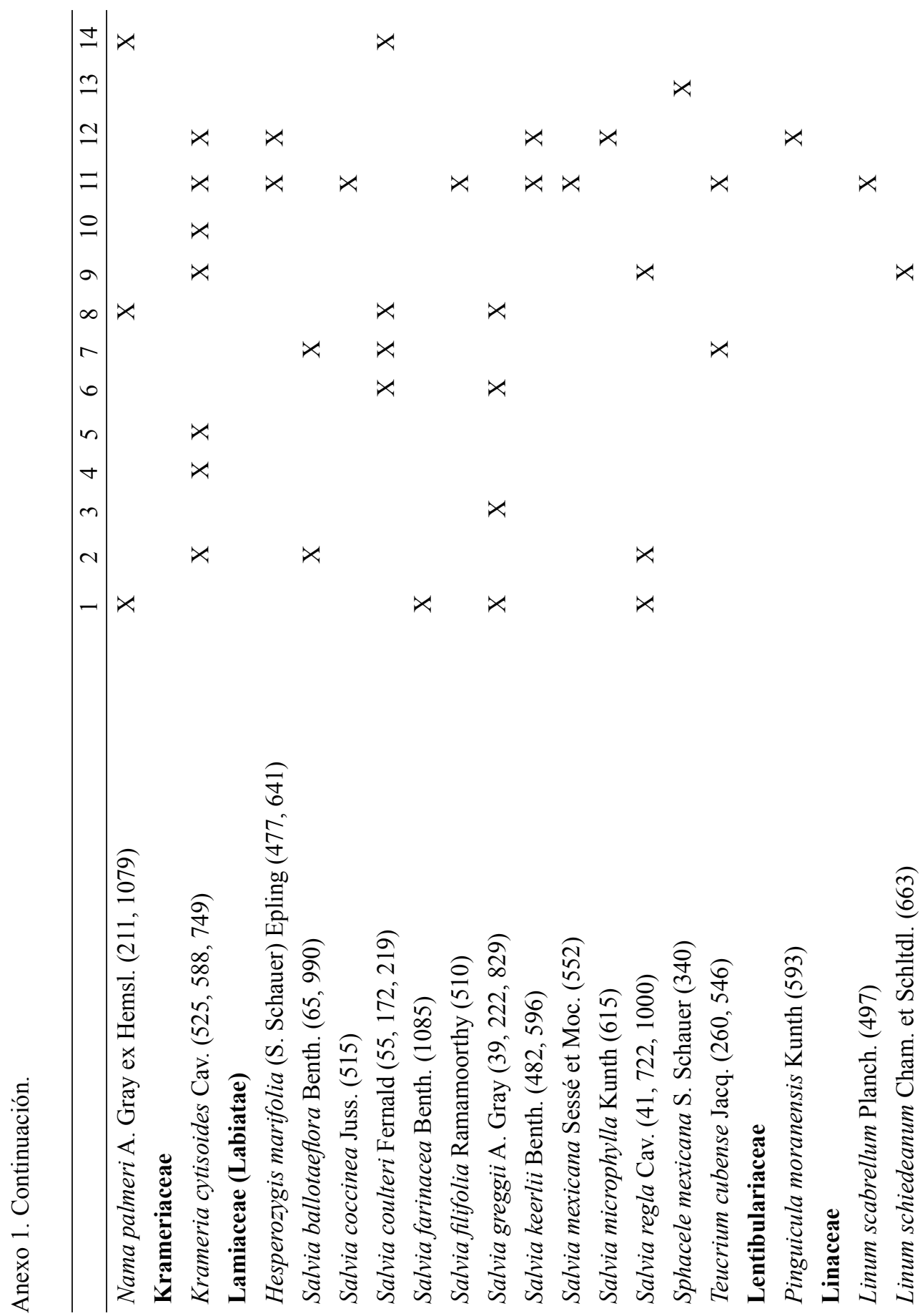


Acta Botanica Mexicana 89: 87-124 (2009)

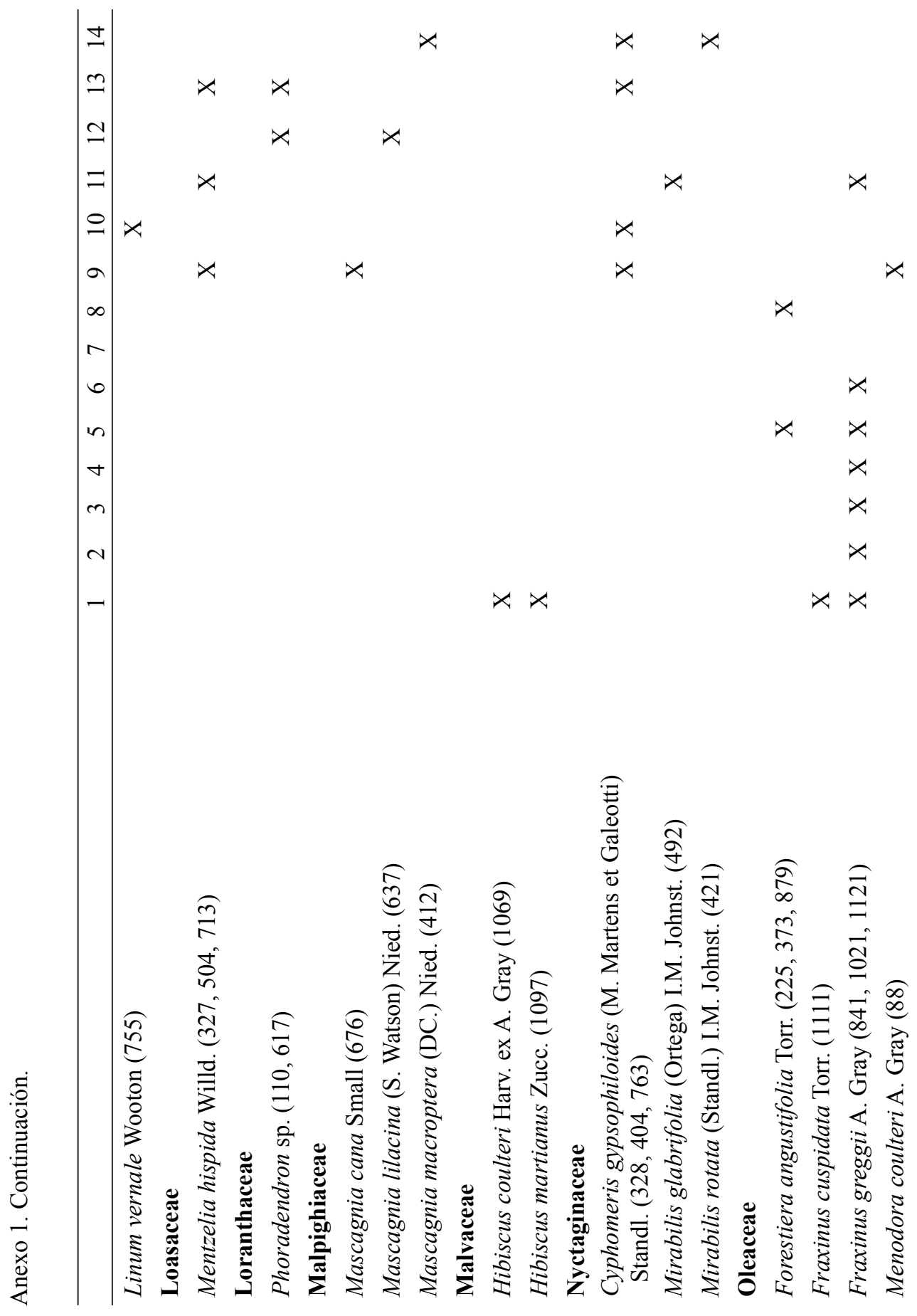


Villarreal Quintanilla et al.: Estudio florístico de los piñonares de Pinus pinceana

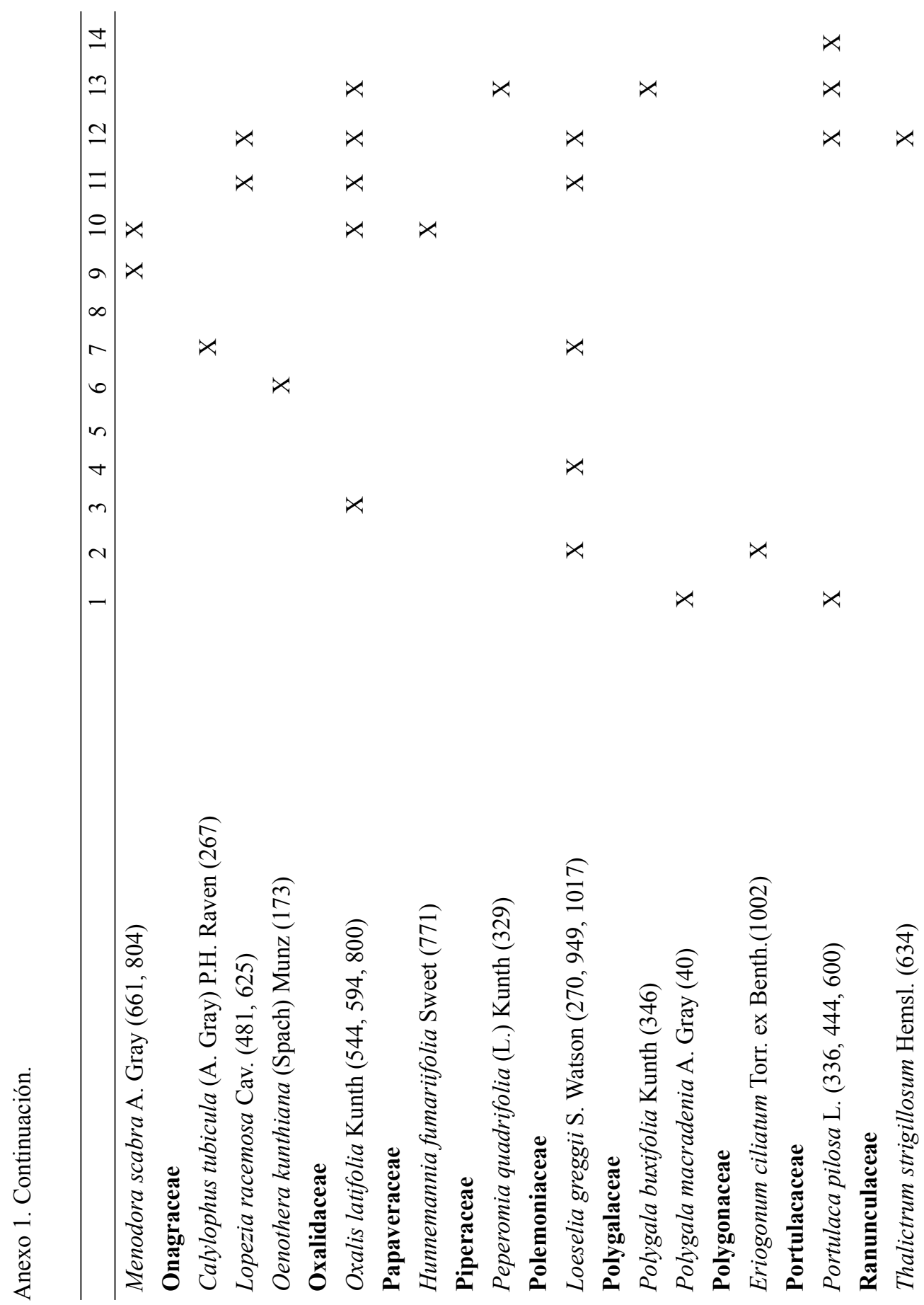


Acta Botanica Mexicana 89: 87-124 (2009)

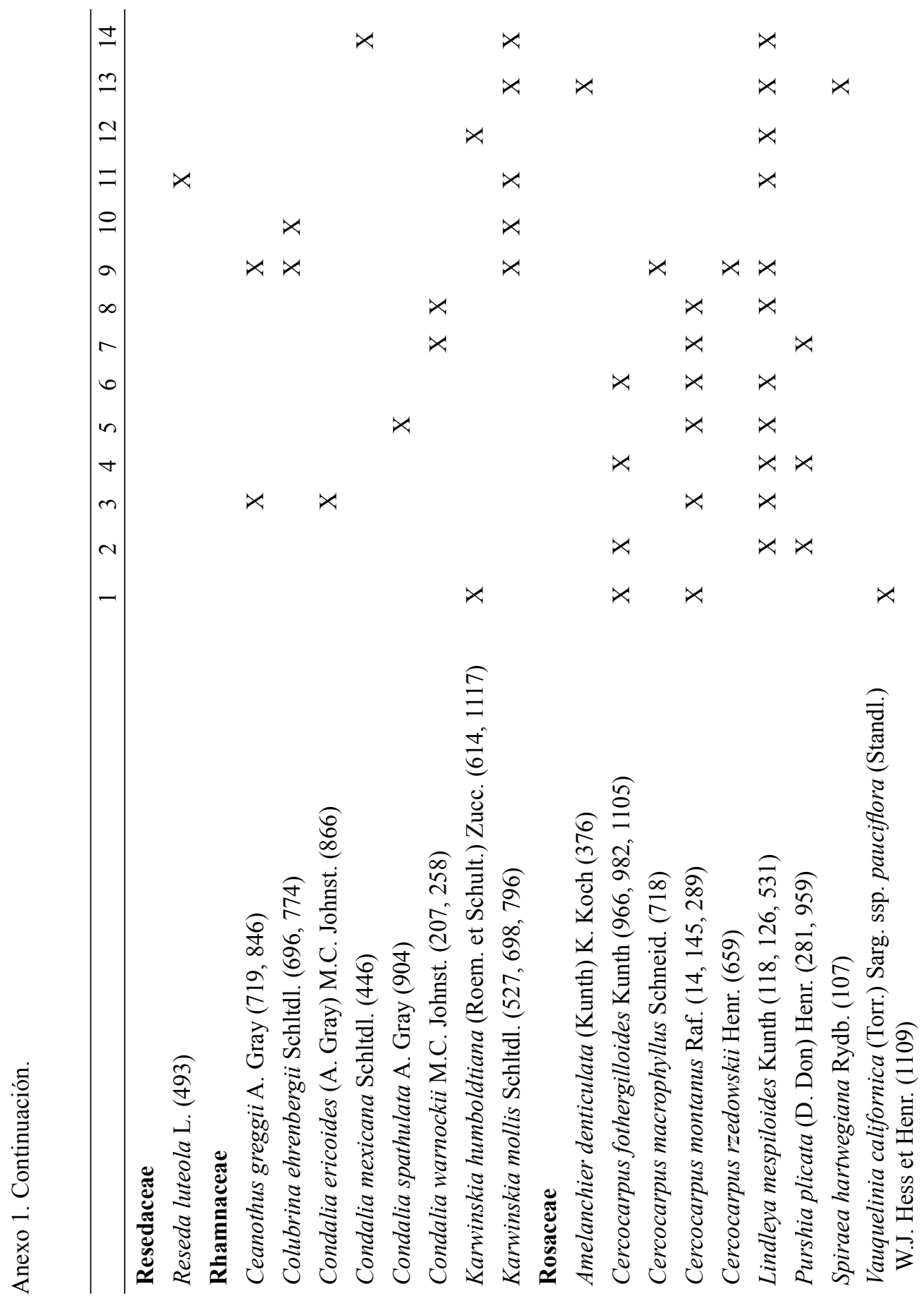


Villarreal Quintanilla et al.: Estudio florístico de los piñonares de Pinus pinceana

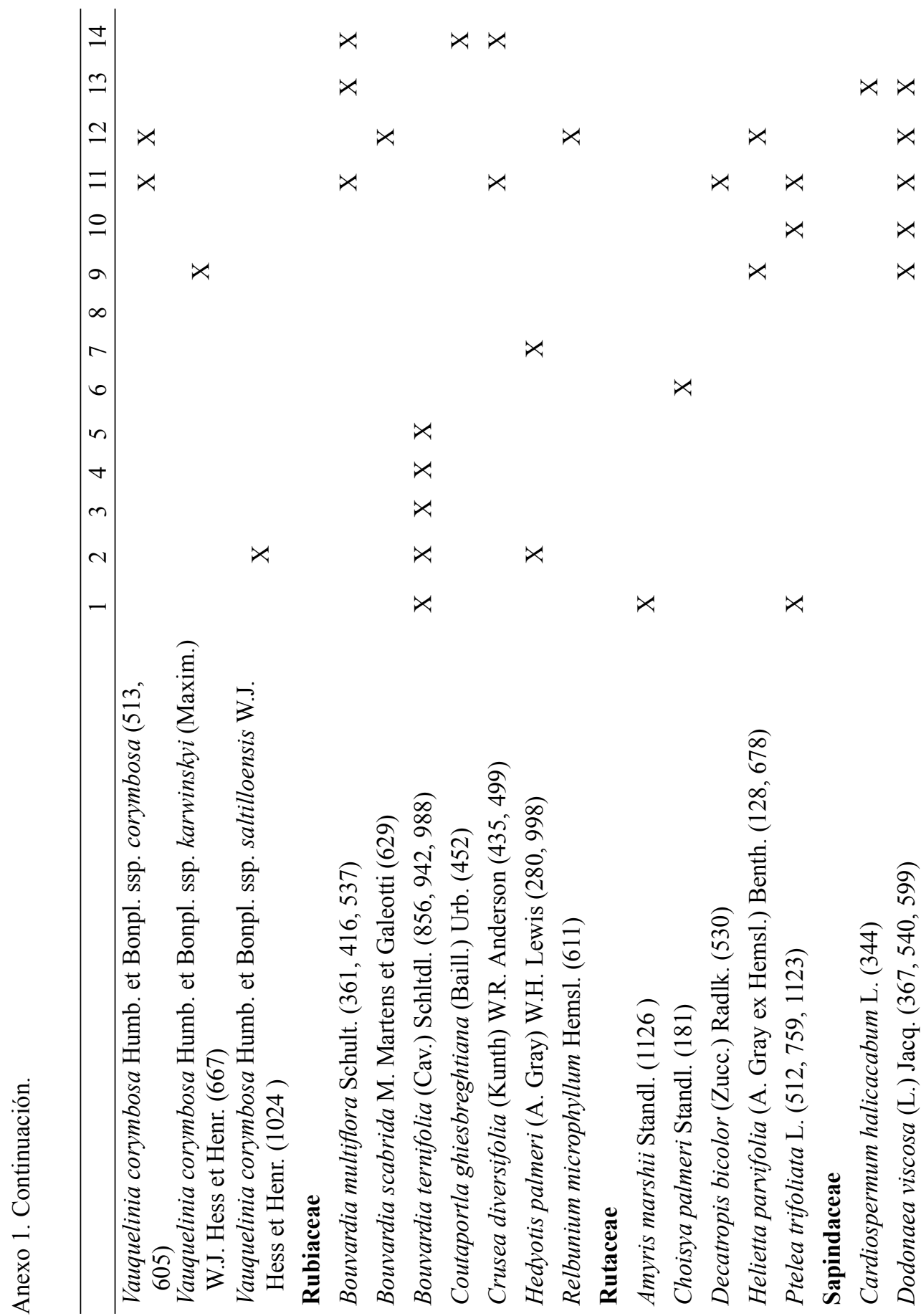


Acta Botanica Mexicana 89: 87-124 (2009)

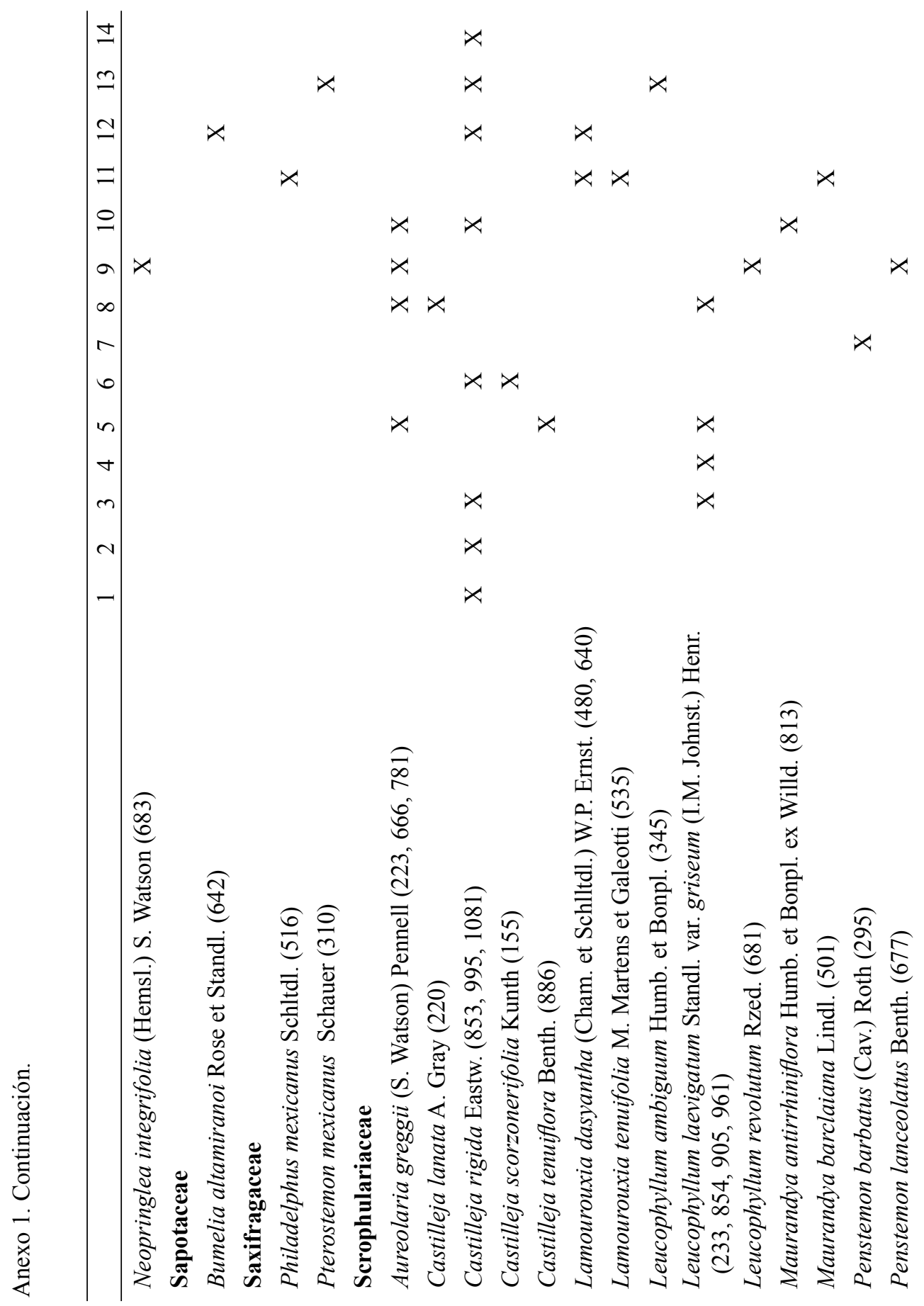


Villarreal Quintanilla et al.: Estudio florístico de los piñonares de Pinus pinceana

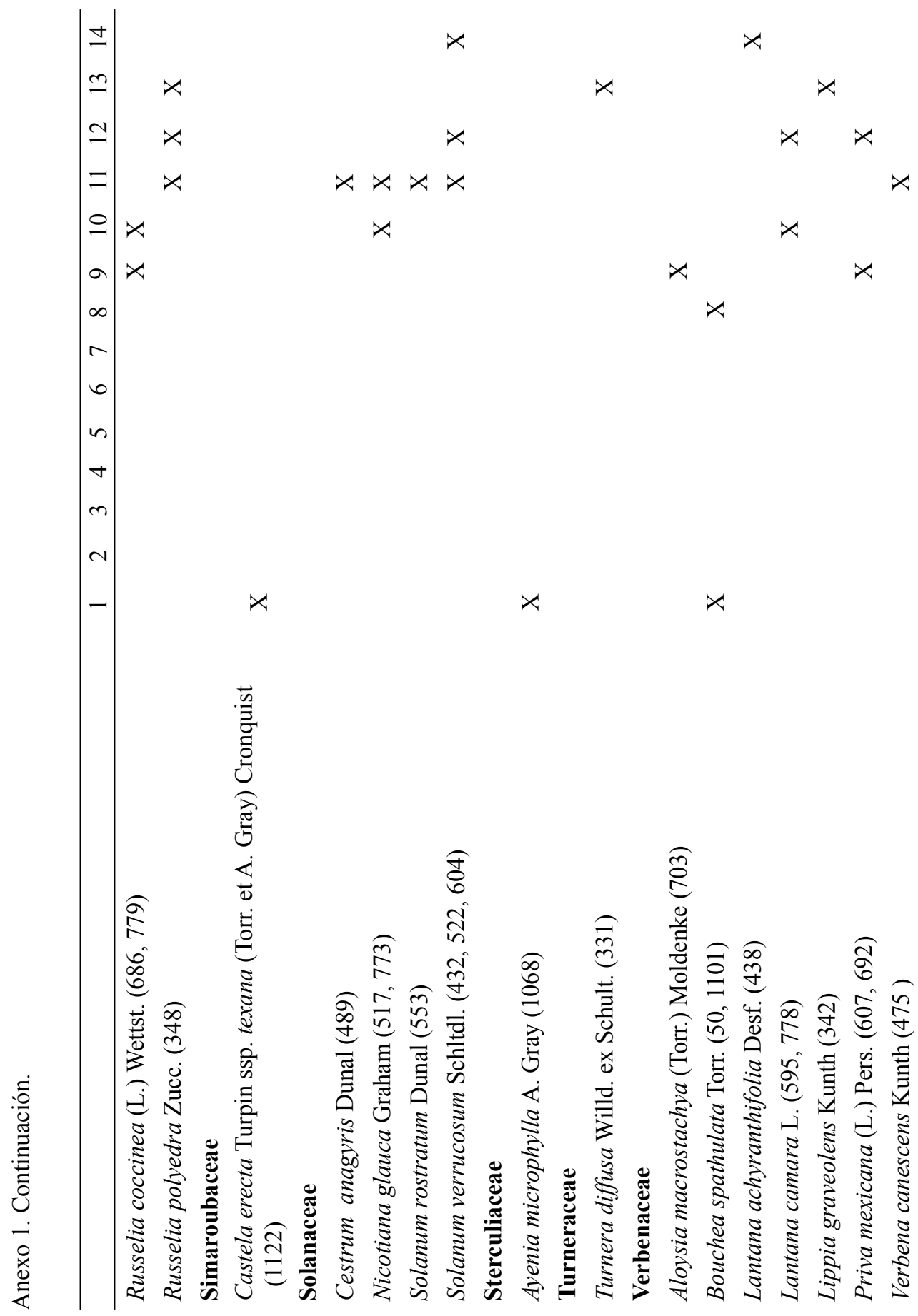


Acta Botanica Mexicana 89: 87-124 (2009)

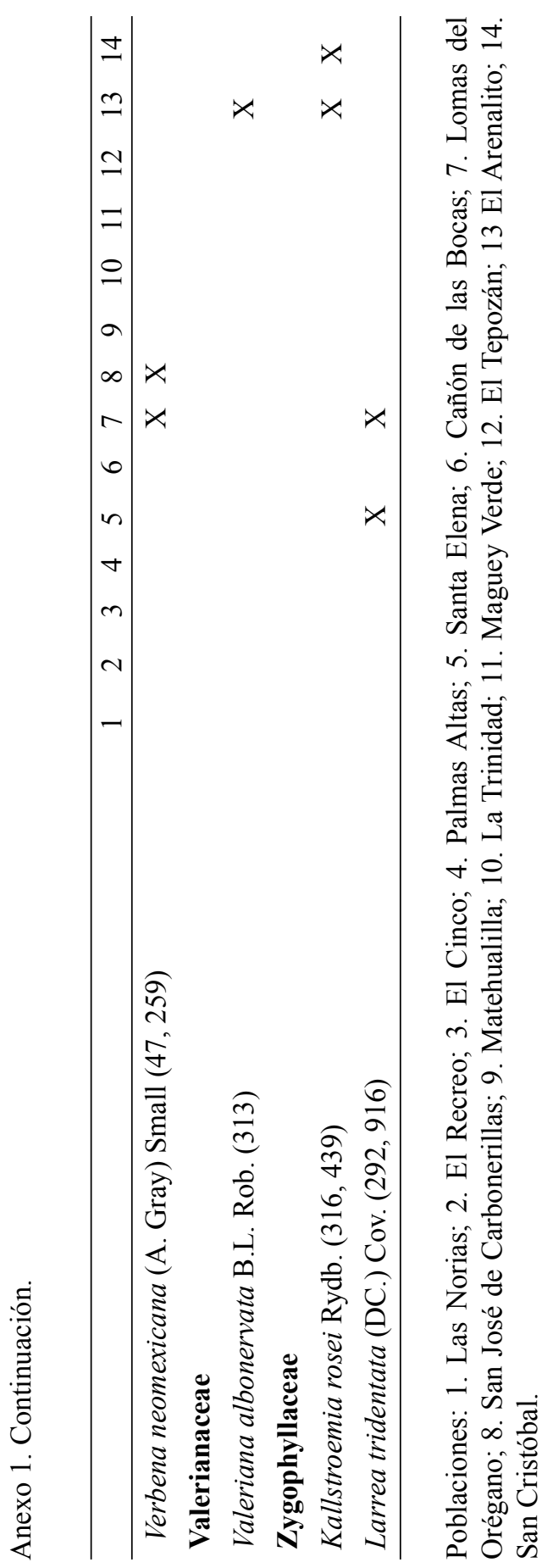

